University of Montana

ScholarWorks at University of Montana

Graduate Student Theses, Dissertations, \&

Professional Papers

1979

\title{
Central auditory function in fluent and disfluent normal speakers
}

Michael K. Wynne

The University of Montana

Follow this and additional works at: https://scholarworks.umt.edu/etd

Let us know how access to this document benefits you.

\section{Recommended Citation}

Wynne, Michael K., "Central auditory function in fluent and disfluent normal speakers" (1979). Graduate Student Theses, Dissertations, \& Professional Papers. 8023.

https://scholarworks.umt.edu/etd/8023

This Thesis is brought to you for free and open access by the Graduate School at ScholarWorks at University of Montana. It has been accepted for inclusion in Graduate Student Theses, Dissertations, \& Professional Papers by an authorized administrator of ScholarWorks at University of Montana. For more information, please contact

scholarworks@mso.umt.edu. 


\title{
COPYRIGHT ACT OF 1976
}

THIS IS AN UNPUBLISHED MANUSCRIPT IN WHICH COPYRIGHT SUBSISTS. ANY FURTHER REPRINTING OF ITS CONTENTS MUST BE APPROVED BY THE AUTHOR.

\author{
Miansfield LibRaRy \\ UNIVERSITY OF MONTANA \\ DATE : \\ 1979
}




\title{
CENTRAL AUDITORY FUNCTION IN FLUENT
}

\section{AND DISFLUENT NORMAL SPEAKERS}

\author{
By \\ Michael K. Wynne \\ B.A., Whitman college, 1976
}

Presented in partial fulfillment of the requirements for the degree of

\author{
Master of Arts \\ UNIVERS ITY OF MONTANA
}

1979

Approved by:
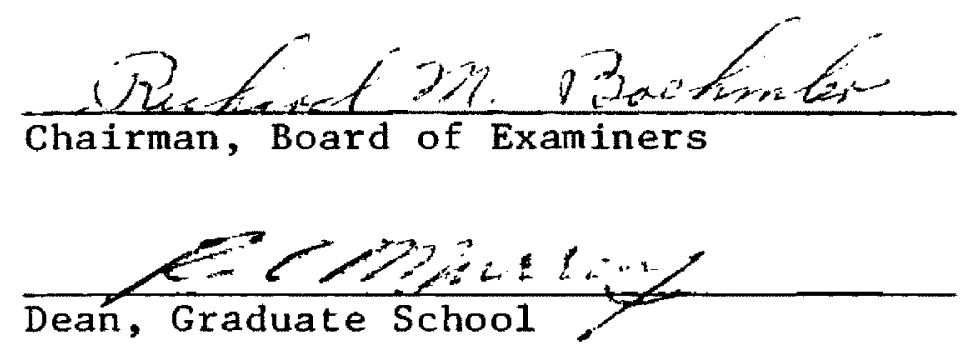

$\frac{s-15-7 q}{\text { Date }}$ 
All rights reserved

INFORMATION TO ALL USERS

The quality of this reproduction is dependent upon the quality of the copy submitted.

In the unlikely event that the author did not send a complete manuscript and there are missing pages, these will be noted. Also, if material had to be removed, a note will indicate the deletion.

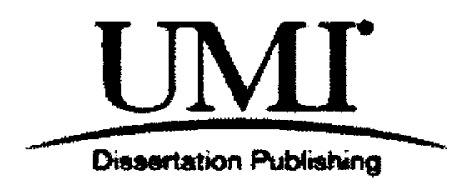

UMI EP38824

Published by ProQuest LLC (2013). Copyright in the Dissertation held by the Author. Microform Edition (C) ProQuest LLC.

All rights reserved. This work is protected against unauthorized copying under Title 17, United States Code

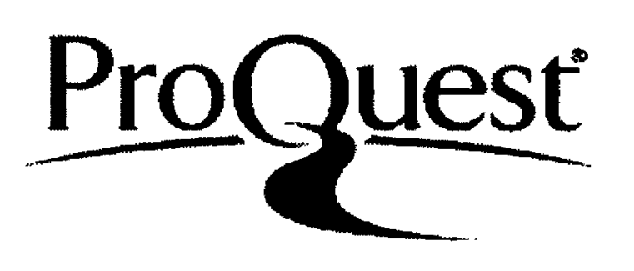

ProQuest LLC.

789 East Eisenhower Parkway

P.O. Box 1346

Ann Arbor, MI $48106-1346$ 
Wynne, Michae1 K., M.A., August, 1979

Communication Sciences

and Disorders

Central Auditory Function in Fluent and Disfluent Normal Speakers

Director: Richard M. Boehmler, Ph.D.

The purpose of the present study was to investigate whether any central auditory differences existed between a group of disfluent normal speakers and a group of fluent normal speakers. It was hypothesized that the disfluent group would demonstrate significantly lower scores on the Synthetic Sentence Identification-Ipsilateral Competing Message (SSI-ICM) test than would the fluent group; however, right ear-left ear differences and the interaction between the groups and ears measured would not be significant. The procedure involved the administration of the SSI-ICM test at a message-to-competition ratio value of -20 to two groups of college students enrolled in an introduction to public speaking course at the University of Montana. The first group (the disfluent group) consisted of 10 male subjects who demonstrated the greatest number of part-word repetitions in a 500 word speech sample. The second group (the matched fluent group) consisted of 10 male subjects who did not produce any part-word repetitions in a 500 word speech sample and whose speaking times were matched with those of the disfluent group. The subjects in both groups were required to meet the following selection criteria: (1) normal middle functioning bilaterally as determined by impedance audiometry; (2) bilateral pure tone thresholds of $10 \mathrm{~dB} \mathrm{HL}$ or better for $500 \mathrm{~Hz}, 1000 \mathrm{~Hz}, 2000 \mathrm{~Hz}$, and $15 \mathrm{~dB} \mathrm{HL}$ or better for $4000 \mathrm{~Hz}$; and (3) no history of stuttering or fluency problems as determined by a self-questionnaire. Each subject was also found to have peripheral speech discrimination skills within normal limits for both ears.

The results of the study indicated that statistically significant differences exist between fluent normal speakers' and disfluent normal speakers' scores on the SSI-ICM test of central auditory function. Although an informal observation suggested that a right ear advantage may exist for both groups, the difference was too small to warrant any comment about ear advantage. Furthermore, the results indicated that the interaction between fluent-disfluent groups and right ear-left ear advantage was not significant. It was suggested that a central auditory deficiency, at least at the brain stem level, may possibly be one of the etiologies for the production of disfluent speech, especially those disfluencies possibly due to a breakdown in syllable production. The implications of the present results on previous studies interpretations of the relationship between central auditory function and fluency breakdown were discussed. Recommendations for further research were also presented. 


\section{ACKNOWLEDGMENTS}

The author wishes to extend his gratitude to the instructors and students of INCO 111 for their cooperation and participation in this study. The author thanks the members of his thesis committee, Dr. Richard M. Boehmler, Dr. Charles D. Parker, Dr. Charles G. Reed, Dr. Robert B. Chaney, Jr., and Dr. James H. Polsin for their helpful comments and suggestions. A special thanks is due to Dr. Boehmler, whose firm guidance and outstanding teaching served as a major source for learning and motivation throughout this project. The author also extends his gratitude to Mrs. Jane Reed for her assistance and encouragement. Finally, the author extends a special thanks to his fiancee and friend, Tia Jah Taylor, for her support and understanding throughout this project.

iii 
ACKNOWLEDGMENTS $\ldots \ldots \ldots \ldots \ldots \ldots \ldots \ldots \ldots \ldots \ldots \ldots \ldots \ldots \ldots \ldots$

LIST OF TABLES $\ldots \ldots \ldots \ldots \ldots \ldots \ldots \ldots \ldots \ldots \ldots \ldots \ldots \ldots$

LIST OF FIGURES $\ldots \ldots \ldots \ldots \ldots \ldots \ldots \ldots \ldots \ldots \ldots \ldots \ldots \ldots \ldots \ldots$

\section{Chapter}

I INTRODUCTION $\ldots \ldots \ldots \ldots \ldots \ldots \ldots \ldots \ldots \ldots \ldots \ldots \ldots \ldots$

II REVIEW OF THE LITERATURE $\ldots \ldots \ldots \ldots \ldots \ldots \ldots \ldots$

III METHOD $\ldots \ldots \ldots \ldots \ldots \ldots \ldots \ldots \ldots \ldots \ldots \ldots \ldots \ldots \ldots \ldots \ldots$

IV $\quad$ RESULTS $\ldots \ldots \ldots \ldots \ldots \ldots \ldots \ldots \ldots \ldots \ldots \ldots \ldots \ldots \ldots$

$\mathrm{v} \quad \mathrm{DISCUSSION} \ldots \ldots \ldots \ldots \ldots \ldots \ldots \ldots \ldots \ldots \ldots \ldots$

vi SUMMARY AND CONCLUSIONS $\ldots \ldots \ldots \ldots \ldots \ldots \ldots \ldots \ldots \ldots \ldots$

BIBLIOGRAPHY $\ldots \ldots \ldots \ldots \ldots \ldots \ldots \ldots \ldots \ldots \ldots \ldots \ldots \ldots \ldots \ldots$

APPENDIX A $\ldots \ldots \ldots \ldots \ldots \ldots \ldots \ldots \ldots \ldots \ldots \ldots \ldots \ldots \ldots \ldots$

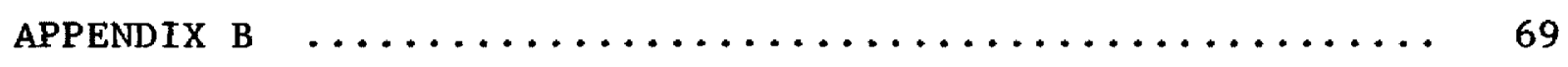

APPENDIX $\mathrm{C} \quad \ldots \ldots \ldots \ldots \ldots \ldots \ldots \ldots \ldots \ldots \ldots \ldots \ldots \ldots \ldots \ldots \ldots \ldots$ 
Table

1 Synthetic Sentence Identification (SSI) Third Order Synthetic Sentences

2 Summary of Subjects Academic Class Levels, Speaking Rates and Number of Part-Word Repetitions during a 500 word Speech

3 t-Test, Means and Standard Deviations for Speaking Rates and Part-Word Repetitions during a 500 Word

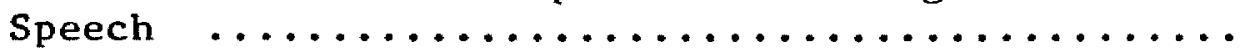

4 Means and Standard Deviations of SSI-ICM Scores for Groups and Ears Tested ................. 44

5 Summary of Analysis of Variance of SSI-ICM Scores .. 45

6 Spearman rho Rank-order Correlation Coefficient and the Ranks of the Disfluent Subjects' Number of Part-Word Repetitions and Average SSI-ICM Score for

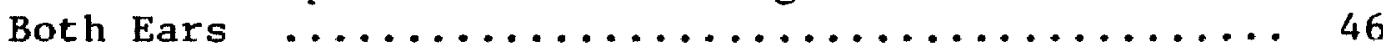


1 Illustration of a Synthetic Sentence IdentificationContralateral Competing Message Test Item $\ldots \ldots \ldots . .8$

2 Illustration of a Synthetic Sentence IdentificationIpsilateral Competing Message Test Item ......... 9

3 Illustration of the Temporal Sequence of a SSW

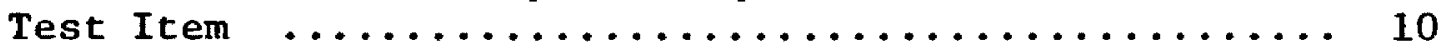

4 Illustration of the Binaural-Separation Test of Dichotic Competing Sentences $\ldots \ldots \ldots \ldots \ldots \ldots \ldots \ldots$

5 Illustration of the Binaural Fusion Test $\ldots \ldots \ldots \ldots \ldots 14$

6 Illustration of the Alternating Speech

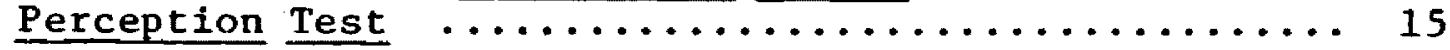

7 Mean SSI-ICM Scores of Groups by

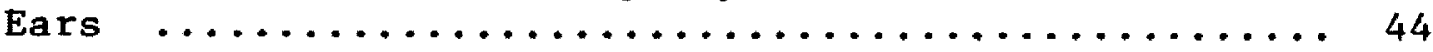




\section{CHAPTER I}

\section{INTRODUCTION}

The nature of the auditory processing skills of stutterers has remained a major issue in stuttering research and theory throughout the 1iterature. With the recent development and advancement of more sophisticated instruments measuring central auditory function, the current literature has begun to address the possible presence of a central auditory dysfunction in the stuttering population. While a few controlled studies have not demonstrated a significant difference in the central auditory mechanisms between stutterers and nonstutterers, the bulk of the literature has suggested that stutterers have a "subtle" central auditory deficiency.

It is this author's hypothesis that the basic relationship between central auditory deficiency and fluency is not a "stutterernonstutterer" difference but a "fluent-disfluent speaker" difference. If this is indeed the case and if fluency behavior is defined along a continuum as is suggested by Bloodstein (1975), then a "subtle" central auditory deficiency should be evident in "nonstuttering" speakers who produce many disfluencies, especially those disfluencies which suggest a breakdown in syllable production. The present study investigated whether any significant differences in central auditory function existed between a group of disfluent normal speakers and a group of fluent normal speakers as measured by a single standard central auditory assessment instrument. The independent variables were defined as presence of specific disfluencies, speaking time, academic class level 
and ear measured. The dependent variable was defined as the central auditory function of the speakers in each group as measured by the Synthetic Sentence Identification-Ipsilateral Competing Message (SSI-ICM) test (Jerger, 1973) at a message-to-competition ratio value of -20 , a procedure which has demonstrated significant differences in the central auditory function between stutterers and nonstutterers. It was predicted that the disfluent group would demonstrate significantly lower scores on the SSI-ICM test than would the fluent group. Thus the study attempted to provide further evidence relating to the hypothesis that a central auditory component exists as at least one of the etiologies in the production of disfluent speech. 


\section{CHAPTER II}

REVIEW OF THE LITERATURE

\section{Central Auditory Dysfunction}

In the classical article by Bocca and Calearo (1963), central auditory function was defined as the capacity to organize simultaneous or successive elements of sound into a definite pattern, thus responding to a fundamental need of the human auditory mechanism. The integration and managenent of such auditory stimuli has lead to the delineation of the specific components of auditory perceptual function such as attention, auditory discrimination, auditory memory, auditory sequencing and auditory synthesis (Toscher and Rupp, 1978; Rampp, 1972). These components are defined as higher cortical functions, suggesting that some form of auditory processing occurs at every level in the auditory channel. Any breakdown in the neurological activities anywhere along the central auditory pathways can lead to anomalies of pattern formation and integration of the auditory information, resulting in a deficit in any one or combination of the components of auditory perceptual function (Toscher and Rupp, 1978).

Carhart (1969) has cited seven possible auditory disorders resulting from the breakdown of neurological activities along the central auditory pathway:

1. Interference with initial ipsilateral transmission of the stimuli at the level of the eighth nerve and probably also the cochlear nuclei.

2. Breakdown in the recoding processes at the cochlear nuclei.

3. Breakdown in the contralateral transmission of monaural signals from the cochlear nuclei to higher levels including the thalamocortical auditory radiations. 
4. Breakdown in binaural cross-correlated functions in the low pontine regions of the trapezoid bodies and in the superior olivary complexes.

5. Dysfunction during the rostral transmission of binaurally integrated information anywhere from the superior olives through the medial geniculate bodies and auditory radiations. Levels would include the middle and upper pons, and the thalamocortical pathways.

6. Dysfunction in the initial sorting and recording of monaural and binaural cross-correlated signals received at the auditory cortex.

7. Breakdown in interhemispheric functions due to lesions affecting the auditory cortex of one or both hemispheres of the transverse interhemispheric auditory pathways of the parietal lobes and the corpus callosum. ( $\mathrm{Pg}$. 41)

Therefore, it appears that the identification and differential diagnosis of a central auditory dysfunction is, at best, a very difficult and complex task requiring procedures which allow the examiner to analyze the numerous and diverse auditory processing activities occuring at many neurological levels (Lynn and Gilroy, 1976).

\section{Evaluation of Central Auditory Function}

Because of the complexity and multi-leveled nature of central auditory processing, highly sensitive speech discrimination procedures often must be used to provide a diagnostic evaluation of central auditory dysfunction. Bocca and Calearo (1963) reported that audiological instruments using pure-tone stimuli have little, if any, diagnostic value for central auditory and perceptual function. These authors provided research findings suggesting that speech tests are far more sensitive for sampling disturbances of perception and integration of auditory stimuli. Furthermore, monaural presentations of short meaningfu1 or meaningless sentences were preferred to words because they circumvent or disregard possible effects of a simultan- 
eous peripheral disorder, thus enhancing the difference between errors due to sensory deficits and those due to central auditory dysfunction. Recent literature has provided a variety of audiological procedures that have been employed in both research and clinical evaluation of central auditory function. In an early study, speaks and Jerger (1965) developed a method for measuring speech identification using synthetic sentences constructed as approximations to real. sentences but which were purposely and systematically diverted from standard.rules of syntax and pragmatics. The synthetic sentences were designed into closed message sets, each of controlled length and controlled relative informational content, thus minimizing the subject's reliance on previous linguistic history. Table 1 presents a message set of third order synthetic sentences provided by Jerger, Speaks and Tramme11 (1968). This instrument, labeled the Synthetic Sentence Identification test, was later utilized in competing message paradigms for measuring central auditory function (Willeford, 1978). Essentially two variations of the Synthetic Sentence Identification test have been adopted as clinical tools measuring central auditory performance. 
TABLE 1

SYNTHETIC SENTENCE IDENTIFICATION (SSI)

Third Order Synthetic Sentences ${ }^{1}$

1. Small boat with a picture has become

2. Built the government with the force almost

3. Go change your car color is red

4. Forward march said the boy had a

5. March around without a care in your

6. That neighbor who said business is better

7. Battle cry and be better than ever

8. Down by the time is real enough

9. Agree with him only to find out

10. Women view men with green paper should

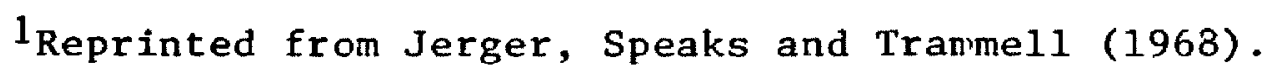


The first mode, the Synthetic Sentence Identification-Contralateral Competing Message (SSI-CCM) test (Jerger, 1973), illustrated in Figure 1, presents the synthetic sentences to one ear while the other ear simultaneously receives a competing message, usually a narrative passage from a common literary work. The second mode, the Synthetic Sentence Identification-Ipsilateral Competing Message (SSI-ICM) test (Jerger, 1973), illustrated in Figure 2, incorporates the competing message in the same ear receiving the synthetic sentences. Performances in both modes are generally measured over a range of message-to-competition ratio (MCR) values. Decreased performances on efther mode suggests a central auditory deficit; however, each mode is believed to identify different sites of lesion. The contralateral competing mode was found to be sensitive in detecting disorders at the temporal lobe level, whereas the ipsilateral competing mode was found to be sensitive in detecting brain stem disorders (Willeford, 1978).

A more widely used measure of central auditory function has been the Staggered Spondaic Word (SSW) test, developed by Katz (1962; 1968; 1973), which has been standardized on a large sample of normal subjects as well as a number of subjects who have demonstrated a variety of peripheral and central problems (Brunt, 1978). Each of the 40 test items is composed of two spondee words recorded in a partially overlapped fashion, with one spondee word presented to each ear at $50 \mathrm{~dB}$ SL in relation to that ear's speech reception threshold. Figure 3 illustrates that each ear receives auditory stimuli in isolation and also in competition with auditory stimuli presented to the opposing ear (Brunt, 1978; Katz, 1977). In this example, the first element "up" is 


\section{FIGURE 1}

\section{ILLUSTRATION OF A SYNTHETIC SENTENCE IDENTIFICATION- CONTRALATERAL COMPETING MESSAGE TEST ITEM}

Primary Message

Women who view men with green paper should
Competing Message

"Everything's got a moral, if only you can find it."

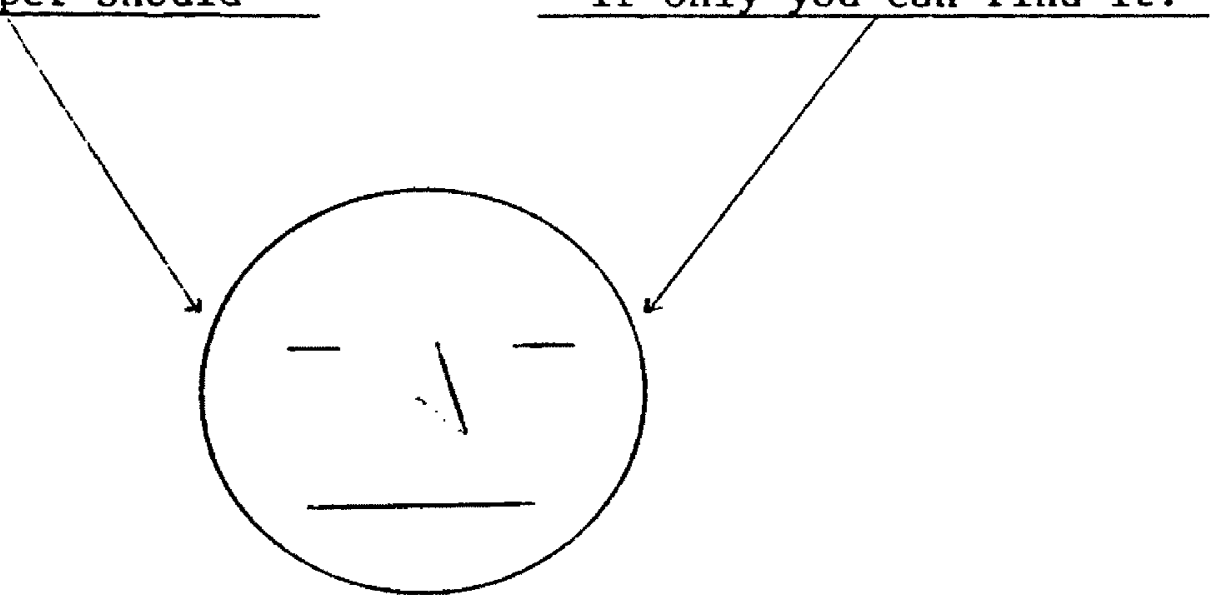


FIGURE 2

\section{ILLUSTRATION OF A SYNTHETIC SENTENCE IDENTIFICATION- IPSILATERAL COMPETING MESSAGE TEST ITEM}

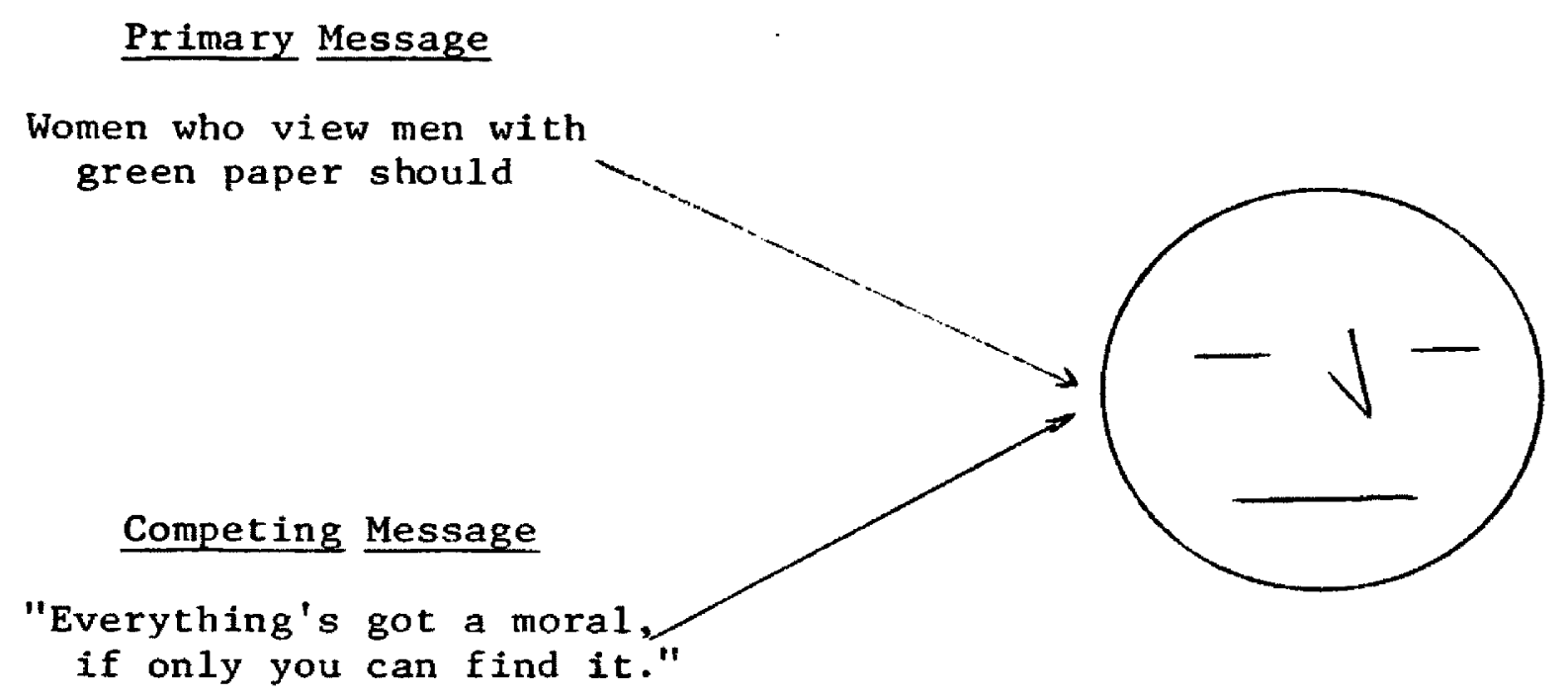




\section{FIGURE 3}

\section{ILLUSTRATION OF THE TEMPORAL SEQUENCE}

OF A SSW TEST ITEM

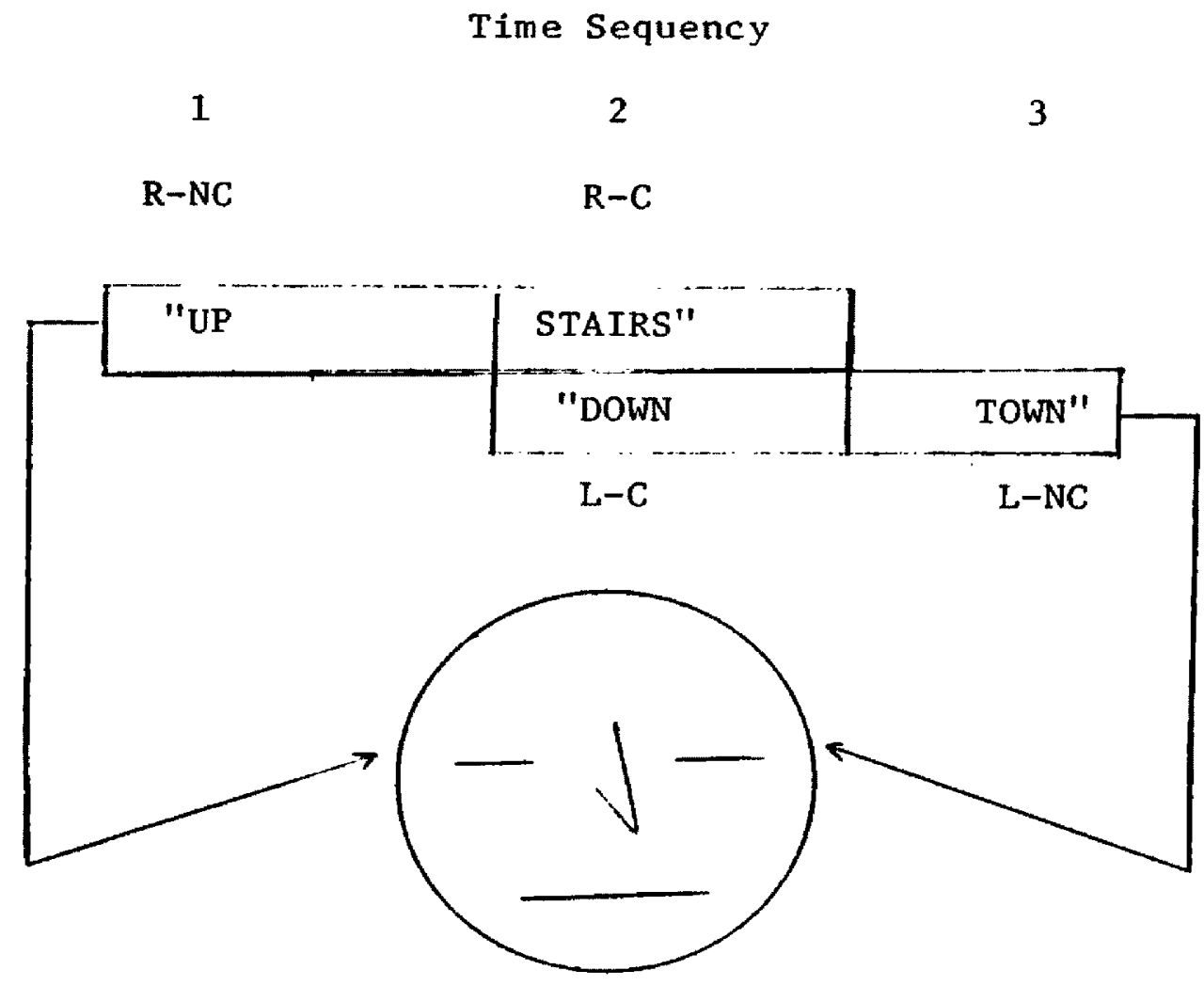


presented in a noncompeting condition to the right ear (R-NC) while "stairs" and "down" are presented as right competing (R-C) and left competing $(\mathrm{L}-\mathrm{C})$ stimuli respectfully. Finally, the last element "town" is presented to the left ear in a noncompeting condition (L-NC). The ear stimulated first changes from item to item. Errors, each monosyllable which is incorrectly reproduced, are scored for each condition and compiled into a total SSW score. The scores are then converted to percentage error and finally the percentage of word discrimination error is subtracted from the SSW error score for the same ear. This Corrected SSW (C-SSW) score reduces the influence of peripheral hearing deficits in measuring the function of an individual central auditory system (Brunt, 1978).

Willeford (1977a; 1977b; 1976) has recently developed a four test battery that attempts to measure several aspects of cortical and brain stem integrity of central auditory function. The first test, the Binaural-Separation Test of Dichotic Competing Sentences developed by Willeford (1968), is illustrated in Figure 4. The primary message is presented to the test ear at $35 \mathrm{~dB}$ SL in reference to the ear's pure tone average (PTA) while a competing message is presented to the nontest ear at $50 \mathrm{~dB}$ SL in reference to its pure tone average. The subject is required to repeat the primary message and ignore the competing message. The second test, the Filtered-Speech Test advocated by Bocca and Calearo (1963), asks the subject to reproduce the monosyllabic words which were passed through an electric filter designed to pass only those frequencies below $500 \mathrm{~Hz}$ before being presented to the test ear. The third test, the Binaural Fusion Test based on the work on brain stem 
F IGURE 4

\section{ILLUSTRATION OF THE BINAURAL-SEPARATION TEST \\ OF DICHOTIC COMPETING SENTENCES}

Primary (35 dB SL)

Competition (50 dB SL)

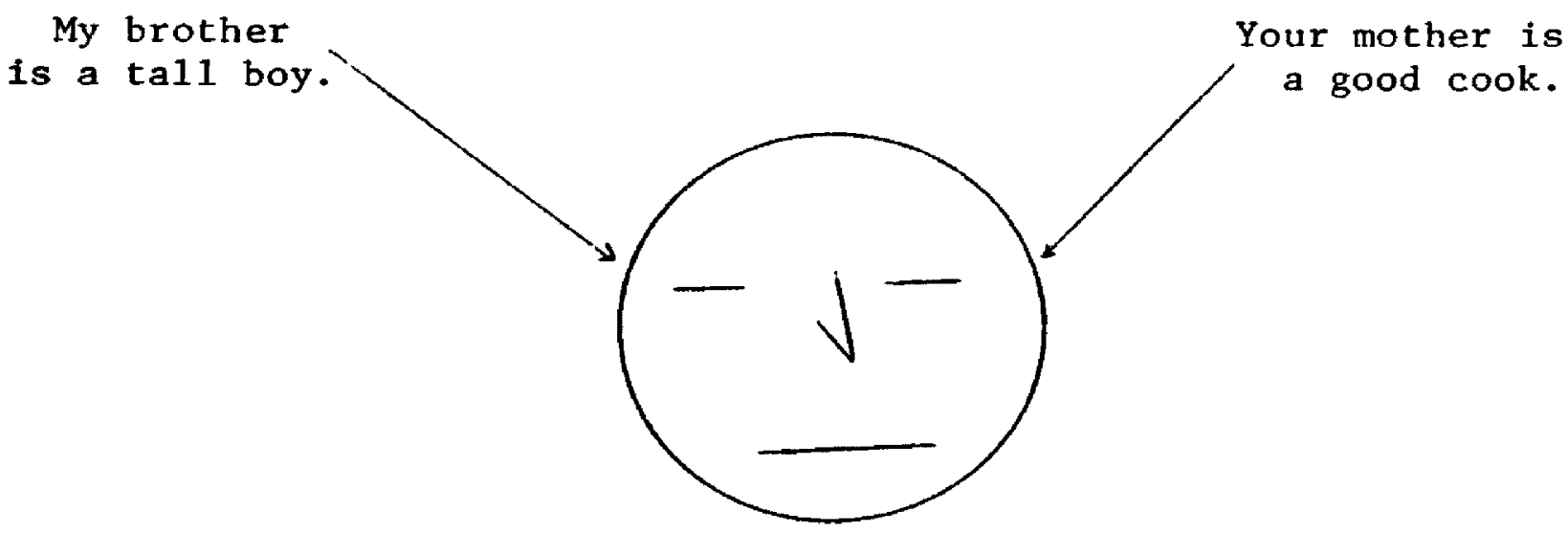


resynthesis by Matzker (1962), is comprised of a low-band-pass segment $(500-700 \mathrm{~Hz})$ of a series of spondee words which is presented to one ear at $30 \mathrm{~dB}$ SL in reference to the ear's threshold at $500 \mathrm{~Hz}$ while a highband-pass segment $(1900-2100 \mathrm{~Hz})$ of those same words is presented to the opposite ear at $30 \mathrm{~dB}$ SL in reference to that ear's threshold at $2000 \mathrm{~Hz}$. The subject is required to fuse both segments together to reproduce the stimulus words as is illustrated by Figure 5 . The final test, the Alternating Speech Perception Test, is illustrated in Figure 6. This test involves stimulus sentences which are presented in alternating bursts of $300 \mathrm{msec}$ durations, first to one ear and then to the other. The subject is asked to repeat the sentence as it is perceived. The Flowers-Coste110 Tests of Central Auditory Abilities (Flowers, Costello and Sma11, 1973) the Composite Auditory Perceptual Test (Butler, Hedrick and Manning, 1973) and the Goldman-FristoeWoodcock Auditory Skills Test Battery (Woodcock, 1976) are also recent test batteries that have attempted to provide a differential evaluation of central auditory function. Although these three instruments have provided some valuable information regarding central auditory processing abilities, each has a number of extraneous variables which remain to be problems in controlled studies (Willeford and Billger, 1978).

Although many audiologists have felt that central auditory testing, using various combinations of the above instruments, produces rather tenuous and speculative audiological and/or neurological data, a number of recent studies have provided evidence of the value of central auditory testing in contributing to the understanding of a variety of clinical disorders. Studies by Jerger and Jerger (1975; 1974) as well 
FIGURE 5

\section{ILLUSTRATION OF THE BINAURAL FUSION TEST}

\section{Low Pass Signal}

$(500-700 \mathrm{~Hz})$

High Pass Signal

$(1900-2100 \mathrm{~Hz})$

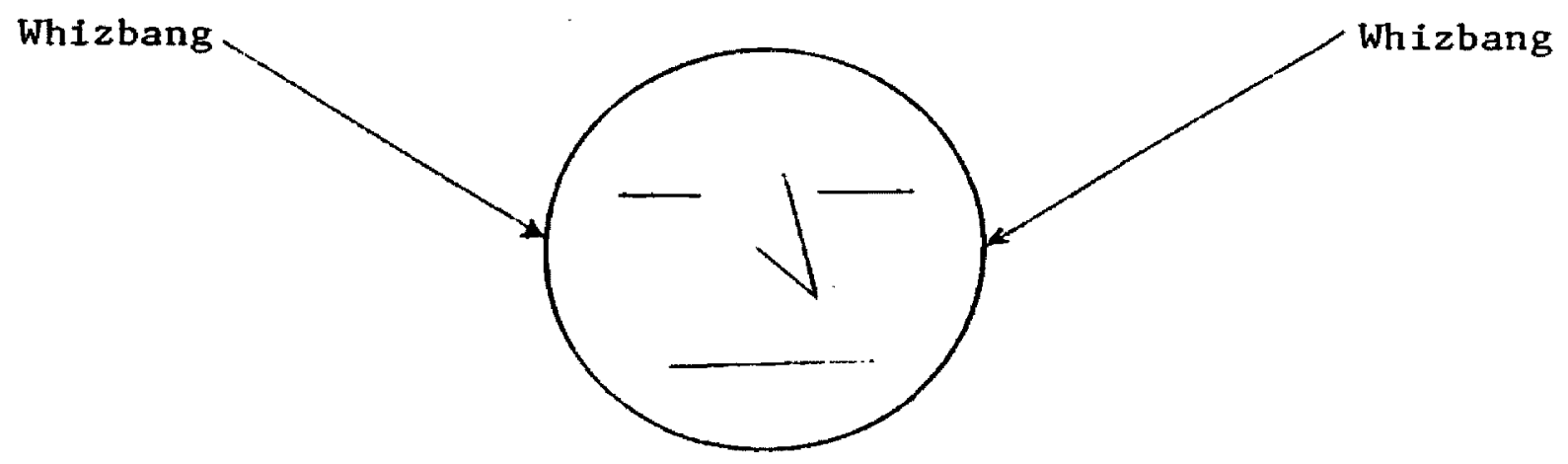


FIGURE 6

\section{ILLUSTRATION OF THE ALTERNATING}

SPEECH PERCEPTION TEST

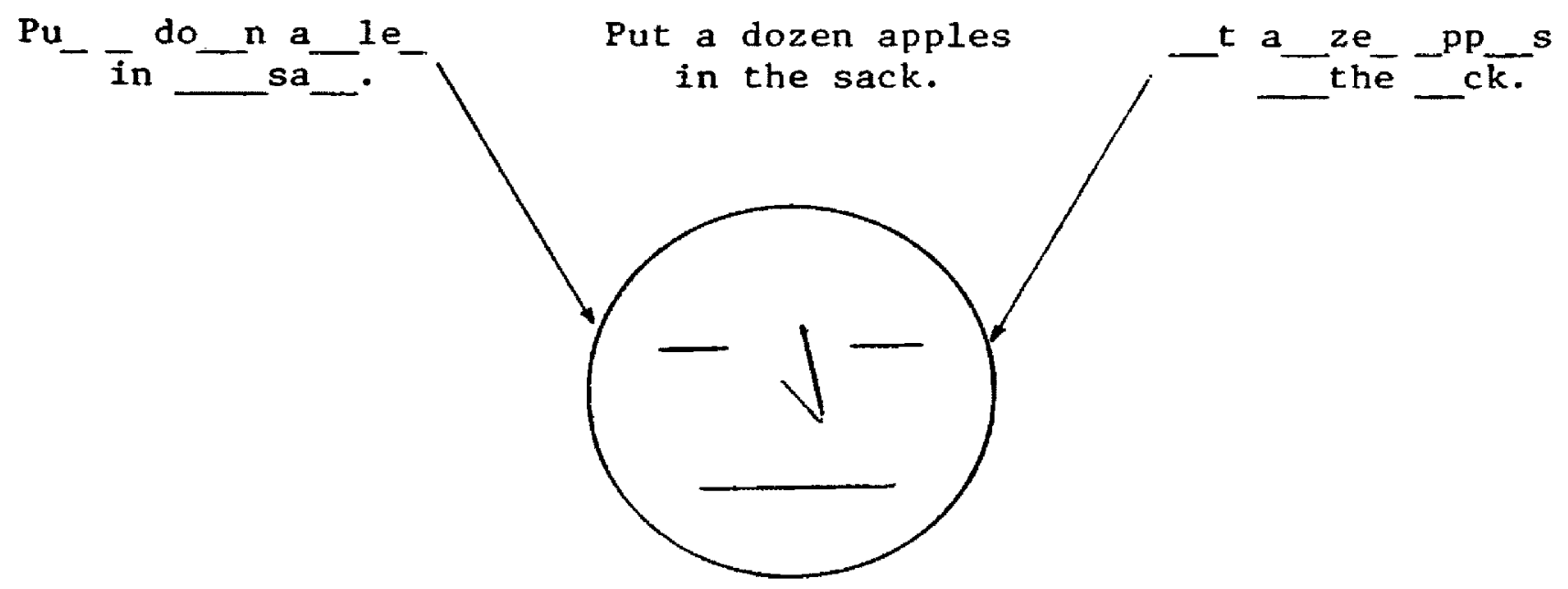


as Lynn, Gilroy and their associates (1977; 1976; 1972a; 1972b) have demonstrated site of lesion in patients with neurological disorders. Willeford $(1978 ; 1977 \mathrm{~b} ; 1976)$, using his test battery of central auditory function, has provided ample evidence demonstrating auditory processing differences in learning disabled children as opposed to normal children. As a group, learning disabled children have been found to show deficits in the perception and integration of speech stimuli at either the brain stem level, the cerebral level or both. Finally, research by Hall and Jerger (1978), Toscher and Rupp (1978), Sommers, Brady and Moore (1975), and Curry and Gregory (1969) has suggested "subtle" auditory processing deficiencies may occur in stutterers as measured by controlled central auditory testing.

The Role of Audition in Stuttering

The nature of the auditory processing skills of stutterers has remained a major issue in stuttering research and theory throughout the literature. Perhaps the first questions concerning the auditory skills of stutterers were raised in discussion of the independent surveys of stuttering in the deaf populations by Albright and Malone (1942), Harms and Malone (1939), and Backus (1938). While some stuttering was found in the deaf populations, it was indeed an extremely rare phenomenon. Bloodstein (1975) reported that varying interpretations of this data have been made ranging from the belief that the parents of deaf children are unlikely to become concerned about the fluency of their children's speech to the assumption that a person may have some auditory ability to monitor his speech if he is to become a stutterer. Nevertheless, a number of theories have evolved suggesting that stuttering is 
the result of inadequate or inappropriate auditory feedback.

Fairbanks (1954) proposed a basic model of the speech mechanism as a servosystem based on auditory feedback. In this closed system, at any moment in speech a controller unit stores an input signal that corresponds to what the speaker intended to say. The input signal is continually compared with feedback about the effector output signal, or what was actually said. An error signal, resulting when the comparison of the signal to what was intended revealed some discrepancy, measures the amount by which the speech signal displayed in the storage device of the controller unit has not been yet produced by the effector. The error signal is then fed into the system to alter the operation of the effector in an attempt to reduce further error signals. Failure to compensate or tolerate such error signals can cause the mechanism to repeat, prolong, hesitate and/or to create other kinds of mistakes of any of the activities in the system. Stuttering is then viewed by Fairbanks as increased disfluency caused by the error signal. Mysak (1966; 1960) extended Fairbanks' (1954) servosystem model to account for disfluent behavior. Basically, he proposed that stuttering is a disturbance of verbal automaticity in tonal flow due to disruptions in any of a series of internal (neurological) or external feedback loops of both speech and language.

Gruber (1965), reviewing Fairbanks' (1954) theory of the servosystem existing in the speaker and some of the experimental literature regarding delayed auditory feedback, believed that information overload in the auditory as compared with the tactual-kinesthetic and proprioceptive monitoring circuits contributed to the fluency breakdown. 
Martin (1970) focused on the function of the comparison criteria between the intended message and the spoken message as the source of the fluency breakdown. The incipient stutterer begins his difficulty by attempting to avoid ordinary unintelligibility or disfluency in his speech. This criterion becomes too stringent and leads to inappropriate evaluation of the feedback signals, thus creating some disfluency. Because of the disfluency, Martin believes that the stutterer may then decide to set a still more conservative criterion which then may lead to more disfluency.

A number of studies have attempted to provide evidence supporting a "servomechanism theory of stuttering." Butler and Stanley (1966), using physiological data on all temporal aspects of audition, programmed a computer model of a servosystem involving an auditory feedback loop similar to the human one proposed by Fairbanks (1954). The authors proposed that if the auditory feedback loop was altered, by either physiological or psychosomatic causes, an instability or interruption of the automatic programing of motor output would occur, resulting in disfluency. They further suggested that the locus of the auditory feedback malfunction may be in the function of the middle ear mechanism. This Idea was not new however. Having demonstrated the effectiveness of various kinds of masking in an immediate and sometimes complete reduction of stuttering, Cherry and Sayers (1956) proposed that a closed cycle feedback system was involved in the production of speech which enabled the speaker to monitor and check his voice production continuously. The authors suggested that stuttering resulted from a type of relaxation oscillation caused by the instability of the 
feedback loop, mediated primarily by the bone-conducted auditory feedback mechanism. These theories have received some support from the work of Horovitz, Johnson, Pearlman, Schaffer and Hedin (1978) who demonstrated a significant difference between mean stapedial reflex thresholds, with and without anxiety status, of fluent and disfluent speakers and from the work of Hall and Jerger (1978) who demonstrated a difference in the acoustic reflex amplitude function between stutterers and nonstutterers.

In contrast to these more general explanations of the servomechanism theory of stuttering, some authors have suggested that specific aberrant temporal relationships are the basis for the breakdown in the auditory processing unit of the speech servomechanism, causing stuttering. Stromstra $(1972 ; 1962 ; 1959 ; 1956)$ indicated that stutterers differ from nonstutterers in terms of interaural phase disparity of bone-conducted side tones. His research suggested that stutterers as a group possess greater asymmetry than nonstutterers ia regard to peripheral auditory transmission and/or central auditory processing of stimuli to the areas within the central nervous system that provide feedback information necessary for speech fluency. Stromstra (1959) stated that the central nervous system can affect the auditory feedback-fluency relationship by a neurological dysfunction which may block or distort the feedback signal preventing any output correction by the servomechanism or by the influence of nonneural, physiological factors on the transmission of the feedback signals through the neurological system. The effect of these alterations of the auditory feedback signals would be a disruption in fluency 
especially at the laryngeal level (Stromstra, 1972). Van Riper (1973) cited a study by Wolf and Wolf (1959) that proposed a similar hypothesis by explaining that stuttering is due to a "dead-time lag" between the auditory input and the motor input of speech. More recently, McFarlane and Prins (1978) demonstrated a slower neural response time in selected motor tasks, particularly in response to auditory stimuli, between stutterers and nonstutterers.

Two fairly recent articles have attempted to account for the empirical data and to integrate the various theories suggesting aberrant temporal relationships between some aspects of auditory feedback and speech activity during stuttering. In the first article, Webster and Lubker (1968) proposed the Auditory Interference Theory (AIT) which states that the stutterer's own auditory feedback provides a source of interference with his motor output control, thus being manifested in the abnormal speech behavior of stuttering. The interference may be the result of the interaction between air-conducted and bone-conducted feedback components producing momentary phase or frequency-induced distortion. Secondary symptoms may develop as learned behaviors to enable the stutterer to cope with or avoid the interference produced by the auditory feedback from their own vocal activity.

Later, Timmons and Boudreau (1972) summarized the various theories of auditory feedback in stuttering behavior. The authors observed that while each theory proposes a faulty monitor mechanism as an etiological factor for stuttering differ in structure and data base, each theory also assumes that neurological components contribute to the disruption of the auditory feedback system. Both psychological and 
physiological factors act as a catalyst for the neurological activities altering the auditory feedback. The authors also point out that tolerance levels for maladaptive responses of the feedback disruptions may be quite variable from individual to individual.

Central Auditory Function in stutterers

Only with the recent development and advancement of more sophisticated central auditory test instruments has the question of central auditory function in stutterers been appropriately addressed. In an early study by Gregory (1964), 30 stutterers and a control group of 10 nonstutterers were administered tests for pure-tone-loudness balances, tests for the median plane localization of pure tones and discrimination tests for monaurally-presented and binaurally-presented distorted as well as unaltered speech stimuli. The groups were found to perform comparably on the loudness balance and localization tasks. Although the stutterers' scores were consistent1y poorer than the nonstutterers' scores in each instance during the speech discrimination tasks, a significant difference was found only on the simultaneous binaural low-passleft, high-pass-right speech discrimination test condition. Gregory concluded that his results did not lend support to a hypothesis that stutterers have a central auditory dysfunction.

In a later study by Curry and Gregory (1969), adult stutterers and nonstutterers were administered one monotic verbal listening task and three dichotic listening tasks, one verbal and two nonverbal. Although both groups performed equally well across three of the listening tasks, significantly different mean absolute between-ears difference 
scores between the two groups were obtained on the Dichotic Word Test which Involved the recall of dichotically presented pairs of consonantvowel-consonant words of high familiarity. Even though a right ear superiority was expected on this task, as was demonstrated by the nonstutterers, $55 \%$ of the stutterers actually obtained higher scores for the left ear. Also a higher percentage of stutterers demonstrated left ear advantages across all of the dichotic listening tasks than did the nonstutterers. The authors interpreted their findings as having little to support the idea that stutterers have auditory receptive difficulties, rather these results suggested differences in the neurophysiological organization in stutterers which may in some way contribute to the disruption of the critical feedback processes for the uninterrupted forward flow of speech.

Three further studies, Perrin (1970), Perrin and Eisenson (1970), and Sommers, Brady and Moore (1975), also demonstrated an absence of the "usual" right ear advantage in dichotic listening tasks with stutterers and suggested that stutterers appear to have a mixed dominance in respect to speech perception and vocalization. Tsunoda and Moriyama (1972) administered standard audiometry and their own cerebral dominance test to a large group of stutterers and normal controls. These authors reported that stutterers varied widely from the predicted right ear advantage for speech stimuli and left ear advantage for non-speech stimuli as was demonstrated by the normal controls. He suggested that among stutterers, there may be a subgroup for which stuttering may be due to abnormal cortical function resulting from minimal brain damage. In contrast, however, Quinn (1972), Cerf and Prins (1974), and Dorman 
and Porter (1975 have reported that dichotic ear preferences of stuttering adults and normal speakers are not significantly different. In an atcempt to account for this discrepancy in the literature, Sussman and MacNeilage (1975) demonstrated no right ear advantage for stutterers in an articulatory tracking task as predicted for normal speakers and suggested that while as a population stutterers have less distinct lateralization of speech related auditory-sensorimotor integration than normal adult speakers, not all stutterers demonstrate such a minimal lateralization. Thus the divergent results are accounted for by a lack of homogeneity among stutterers. A recent study by Cross, Shadden and Luper (1979) investigated the effects of right vs left ear stimulus presentation on the voice reaction times of stutterers and nonstutterers. Although the stutterers exhibited significantly longer and more variable voice reaction times than did nonstutterers, the two groups did not demonstrate any left or right ear effects on stimulus presentations. Still the authors speculated that stuttering may be due, in part, to inherent rather than learned factors.

Administering a comprehensive central auditory assessment battery, Hall and Jerger (1978) failed to demonstrate substantial central auditory disorders in stutterers. However, relative to a control group of normal speakers, stutterers' performances on three central auditory procedures were depressed, although not significantly; acoustic reflex amplitude functions, Synthetic Sentence Identification-Ipsilateral Competing Messages (SSI-ICM) test, and the Staggered Spondaic Word (SSW) test. Specifically, on the acoustic reflex amplitude curves, relating the changes in acoustic reflex amplitude to a uniform increase in the 
intensity of the stimulus, the stutterers consistently demonstrated a more gradual slope of the amplitude function when compared to normal speakers. The authors found that the scores for the stutterers on the SSI-ICM test were poorer than those for the control group across all message-to-competition ratios $(M C R=0, M C R=-10, M C R=-20)$ with the data demonstrating the maximum difference between the two groups on the $M C R=-20$ conditions. All subjects in both groups performed with $100 \%$ accuracy on the Synthetic Sentence Identification-Contralateral Competing Messages (SSI-ICM) test. Finally the stuttering group demonstrated no right ear advantage on the SSW test; whereas, the control group demonstrated an insignificant $2 \%$ right ear advantage based on percentages of correct scores. Hall and Jerger interpreted these results to suggest that stutterers present evidence of a "subtle" central auditory deficiency, possibly involving auditory function at the brain stem level.

Toscher and Rupp (1978) specifically compared the performances of stutterers and normally fluent speakers on the Synthetic Sentence Identification (SSI) test to investigate the presence of subtle, neurologically based auditory processing difficulties in stutterers. The results revealed that the two groups performed equally well on the SSI orientation and the Synthetic Sentence Identification-Contralateral Competing Message (SSI-CCM) subtest; however, the performances of the stutterers were significantly poorer than those of the nonstutterers on the Synthetic Sentence Identification-Ipsilateral Competing Message (SSI-ICM) subtest across a11 three message-to-competition ratio values $(M C R=0, M C R=-10, M C R=-20)$. The differences between the two groups' 
performances were found to be the largest on the MCR=-20 condition, confirming the results of the earlier study of Hall and Jerger (1978). Thus it appears that the SSI-ICM test at a message-to-competition ratio value of -20 may be the most sensitive current instrument measuring central auditory differences between fluent and disfluent populations. No significant differences were demonstrated in the degree of ear difference between the two groups. Toscher and Rupp suggested that a neurological central auditory dysfunction may be, at least, one of the underlying etiologies of stuttering. 
The Continuity Theory of Stuttering

Although the previous studies have demonstrated differences in the central auditory functions of stutterers when compared to nonstutterers, they did not investigate the relationship between the central auditory function and the number of disfluencies produced by the subjects in the control (fluent) groups. A number of studies have provided evidence that the variables which have demonstrated significant behavioral differences between stutterers and nonstutterers may also demonstrate behavioral differences between fluent and disfluent normal speakers (Bloodstein, 1975). Bloodstein builds this argument to form his continuity theory of stuttering. This theory is heavily supported by studies indicating that nonstutterers show similar if not identical patterns of adaptation effects as illustrated by stutterers as well as studies demonstrating that the modification of the disfluencies of normal speakers by response contingent stimuli parallels the modification of the disfluencies of stutterers by response contingent stimuli (Bloodstein, 1975). If fluency behavior is indeed defined along a continuum, then a similar "subtle" central auditory deficiency should be evident in "nonstuttering" speakers who produce many disfluencies.

\section{Categories of Disfluency}

The previous studies comparing the central auditory functions of stutterers and nonstutterers have employed gross global definitions of fluency behavior, perhaps resulting in rather heterogeneous groups of stutterers and nonstutterers. Johnson (1961) has provided frequency distributions across a number of verbal tasks for seven categories of 
disfluencies in stutterers and nonstutterers: interjections, partword repetitions, word repetitions, phrase repetitions, revisions, incomplete phrases, broken words, and prolonged sounds. In an examination of his data, Johnson observed that the frequency of part-word repetitions was the single most delineating factor separating stutterers from nonstutterers in a speech task. In addition, the data indicated that while nonstutterers were decidedly more fluent in a reading task than in a speaking task, their number of part-word repetitions increased in the reading task suggesting that part-word repetitions may not be as directly related to language formulation variables as are the other categories of disfluencies. It was postulated by the present author that part-word repetitions and sound prolongations would be a more sensitive indicator of fluency breakdown due to a central auditory deficiency than would the other categories of disfluencies. That is, if the auditory feedback of the speech signal was deficient, the speaker would fail to appropriately monitor his speech. This, in turn, would disrupt the production of the syllable pulse, which is the basic physiological unit of speech production (Perkins, 1977; Stetson, 1951). The manifestations of these breakdowns in syllable production would be seen as part-word repetitions and sound prolongations. Conture and Brayton (1975) provide some evidence towards this reasoning by demonstrating that part-word repetitions and sound prolongations were the two categories of disfluency whose frequency of occurance was clearly influenced by the introduction of noise conditions. However, the authors point out that only the frequency of occurance of the part-word repetitions was significantly affected by 
the noise conditions. This data suggest that research should carefully consider the types of disfluencies produced in the experimental groups, especially in those studies investigating auditory differences between stutterers and nonstutterers. 
Statement of the Purpose of the Present Study

On the basis of the literature indicating central auditory differences between stutterers and nonstutterers, the literature proposing that fluency behavior is defined along a continuum, and the 1iterature suggesting that part-word repetitions may be the most sensitive indicator of fluency breakdown due to a central auditory deficiency, it is this author's hypothesis that the basic relationship between central auditory deficiency and fluency behavior is not a "stutterernonstutterer" difference but a "fluent-disfluent speaker" difference. Specifically, if the basic relationship between central auditory deficiency and fluency behavior is a "fluent-disfluent speaker" difference rather than a "stutterer-nonstutterer" difference, then a "subtle" central auditory deficiency should be evident in "nonstuttering" speakers who produce many disfluencies, especially those disfluencies which suggest a breakdown in syllable production such as part-word repetitions. Thus the present study investigated whether any significant differences in central auditory function exist between a group of disfluent normal speakers and a group of fluent normal speakers. The disfluent group was specifically defined by the speakers' total number of part-word repetitions during a 500 word speech sample. The independent variables were defined as presence of specific disfluencies, speaking time, academic class level and ear measured. The dependent variable was defined as the central auditory function of the speakers in each group as measured by the Synthetic Sentence Identification-Ipsilateral Competing Message (SSI-ICM) test at a message-tocompetition ratio value of -20 , a procedure which has demonstrated 
significant differences in the central auditory function between stutterers and nonstutterers. The author predicted that the disfluent group would demonstrate significantly lower scores on the SSI-ICM test than would the fluent group; however, right ear-left ear differences and the interaction between the groups and ears measured would not be significant. 


\section{CHAPTER III}

METHOD

In order to investigate the experimental hypothesis that disfluent normal speakers will demonstrate lower scores on the Synthetic Sentence Identification-Ipsilateral Competing Message (SSI-ICM) test at a message-to-competition ratio value of -20 , the following procedures were used.

\section{Subjects}

A Total of 73 male subjects ranging in age from 18 to 27 years were used in the present study. All of the subjects were enrolled in a co-ed introduction to public speaking class at the University of Montana. Of the 140 male students registered in the class, whose total enrollment was 205 students, approximately 52\% volunteered to participate in the study. Two groups were specifically selected from the above population. All of the subjects in the two groups were required to meet the following selection criteria: (1) male gender; (2) normal middle ear functioning bilaterally as determined by impedance audiometry; (3) bilateral pure tone thresholds of $10 \mathrm{~dB} H L$ or better for $500 \mathrm{~Hz}, 1000 \mathrm{~Hz}$, $2000 \mathrm{~Hz}$, and $15 \mathrm{~dB} \mathrm{HL}$ or better at $400 \mathrm{~Hz}$; (4) no history of stuttering or fluency problems as determined by a self-questionnaire (Appendix A); and (5) volitional participation in the study.

By requiring all subjects to be male, the study attempted to control for any possible confounding vartables which may have been attributed to the sex of the subject. The relationship between fluency 
behavior and the sex of the speaker has been investigated throughout the literature with a number of studies demonstrating that the sex of the speaker is a variable which influences his or her fluency behavior. It was not within the scope of the present study to investigate any sex related variables on the subjects' speaking behaviors and/or central auditory functions.

The subjects in Group DG (the disfluent group) consisted of 10 male subjects who exhibited the greatest number of part-word repetitions during the presentation of a 500 word speech compared by each respective subject. The subjects in Group MG (the matched fluent group) consisted of 10 male subjects who did not produce any part-word repetitions throughout the presentation of their 500 word speech and whose speaking times matched that of the disfluent group. Matching speaking times was employed to control for the articulatory rates of the speakers. The fluent subject with the closest corresponding speaking time to each disfluent subject within a 6 second range and at the same academic class level was chosen for the matched group. However, if a fluent subject could not be found in that 6 second range at the same academic level, the fluent subject with the closest corresponding speaking time was chosen from an adjacent academic class level for the matched group. Priority was given to the matching of the speaking times of the subjects with a secondary consideration of minimizing any academic class level differences between subjects.

\section{Instrumentation}

Al1 speech samples were recorded on Maxel1 C-120 U1tra-Dynamic Cassette Tapes by a Sony TC-110 A Cassette Tape Recorder. Each speech 
sample was recorded in the subjects' assigned classrooms for the introduction to public speaking class.

All audiological testing was conducted in a double-walled Industrial Acoustic Company (IAC) sound-treated room at the University of Montana Speech, Hearing and Language Clinic. Ambient noise measurements of the sound-treated room were conducted prior to the audiolological evaluation of the subjects, and the levels were found to be within acceptable limits in reference to ANSI 1977 standards. Tympanometry for the assessment of middle ear functioning was accomplished with an American Electromedics Acoustic Model 83 Impedance Audiometer. Pure tone, speech and central auditory testing was carried out on a Grason-Stadlex 1701-D Audiometer with the auditory signals delivered to the ear via TDH-39 earphones with MX-41/AR supra-aural cushions. Any testing which involved the playback of an audiotape through the audiometer was accomplished with a Sony TC-366 Three Head Stereo Tape Recorder. Periodic intensity and frequency calibration of the GrasonStadler 1701-D Audiometer for the conventional frequencies was performed with a Bruel and Kjaer (B\&K) Sound Level Meter (2203) connected to a B\&K Condenser Microphone (4121) and combined with a B\&K Artificial Ear (4152).

A11 of the audiological procedures administered to groups DG and MG have been previously described in detail elsewhere (Jerger, Speaks and Tramme11, 1968; Katz, 1978). The synthetic sentence stimuli used in this study consisted of a set of 10 third order approximations published by Jerger, Speaks and Trammel1 (1968). Twenty-one standard notebooksized ( $\left.8 \frac{1}{2} " \times 11^{\prime \prime}\right)$ score sheets were placed before each subject during 
the testing to provide him with a closed set of response sentences (Appendix B). The synthetic sentence stimuli as well as the ipsilateral competing message from Lewis Carroll's Alice in Wonderland were recorded by the experimenter on a Sony Tc-366 Three Head Stereo Tape Recorder.

\section{$\underline{\text { Procedure }}$}

A11 of the 129 subjects were assigned by their respective instructors to present in class a 5 to 7 minute informative speech on a topic of their choice (Polsin, 1976). The speeches were recorded, then analyzed by the experimenter for speaking times, measured by the total amount of time required to speak the first 500 words of the speech (Sander, 1961; Young, 1961), and the number of part-word repetitions present in those first 500 words. Ten speech samples, selected at random, were analyzed by an experienced clinician and external and internal reliability coefficients were determined to evaluate the accuracy of the categorization of the subjects by their number of disfluencies and speaking times. Any subject with a passage less than 500 words in length was rejected. A part-word repetition was defined as any moment during which any part of an intended word, whether it was sounds or a syllable, was repeated. Each time a part-word repetition occurred, it was counted as an individual unit of disfluency. This definition of part-word repetitions was based on Johnson's (1961) definition of the total number of units of repetition rather than the total number of instances of repetition. After the number of the part-word repetitions for each subject was totalled, the ten male subjects who demonstrated the greatest number of part-word repetitions (at least one) during the 
speech task were placed in Group DG. Group MG was composed of ten male subjects who did not exhibit any part-word repetitions during the speech task and were matched on the speaking times.

The subjects in the two groups were then scheduled for appointments for the audiological testing. Each subject in these two groups was tested in a single session of fifteen to twenty minutes in duration. Equipment was calibrated biologically prior to the audiological evaluation of each subject. All of the audiological procedures were administered to each subject in the following order: impedance audiometry, pure tone audiometry, speech discrimination testing, and finally the Synthetic Sentence Identification-Ipsilateral Competing Message test. The order of the presentation of the auditory stimuli to the right ear channel and the left ear channel was counterbalanced. Speech discrimination testing was administered with the recorded presentations of $\mathrm{PB}$ words at $40 \mathrm{~dB} \mathrm{HL}$ to each ear.

During the Synthetic Sentence Identification-Ipsilateral Competing Message test, the sentence stimuli were presented at $60 \mathrm{~dB}$ HL without a competing message initially to familiarize the subjects with the test material and control for learning variables. All sentence stimuli were then presented at $40 \mathrm{~dB} \mathrm{HL}$ and the message-to-competition ratio value was -20 ( $40 \mathrm{~dB} \mathrm{HL}$ message to $60 \mathrm{~dB} \mathrm{HL}$ competition). The $M C R=-20$ value was selected for the present study because Toscher and Rupp (1978) as well as Hall and Jerger (1978) demonstrated that the maximum difference between stutterers and normal speakers on the SSIICM test occurred at this value. Five randomized sets of sentence stimuli, based on a table of random numbers, were available for the 
evaluations. Each ear was randomly assigned a set of sentence stimuli for the test procedure. Each subject was instructed to 1isten to the sentence stimuli and, with the help of the score sheets, identify the number of the sentence which was presented. Each subject had 5 seconds to respond before the next sentence stimuli were presented. Responses to each 10 sentence set were scored from 0 to 10 , with 10 indicating that all sentence stimuli were identified correctly.

A split-plot $2 \times 2$ analysis of variance with one repeated measure (Kirk, 1969) was performed on the data to determine the significance of the differences among means. The coefficient of risk was selected at $0.10(\alpha=0.10)$ prior to the collection of the data. This level of confidence was determined in an attempt to reduce the probability of a Type II error (rejecting the true hypothesis), although it was recognized that this level of confidence also enhances the probability of a Type I error (accepting the false hypothesis). However, the relative cost to society of a Type I error occurring in this study was determined to be small since this study would generate additional research before any therapy implications would be applied. It was predicted that the main effect between the groups would be significant; whereas, the main effect between the ears and the interaction between the groups and ears would not be significant. In addition, if the main effect between the groups was significant, then a Spearman rho rankorder correlation coefficient would be determined from the data obtained In the disfluent group to investigate the relationship between the rank of each subject's number of part-word repetitions and the rank of eacis subject's average SSI-ICM score for both ears. 


\section{CHAPTER IV}

\section{RESULTS}

The experimental hypothesis of the present study proposed that a group of ten male disfluent normal speakers would obtain lower scores on a test of central auditory function than would a matched group of ten male fluent normal speakers. The data used to test this hypothesis were each subject's speaking time for a 500 word speech, number of partword repetitions produced during a 500 word speech sample, and the score for each ear on the Synthetic Sentence Identification-Ipsilateral

Competing Message (SSI-ICM) test of central auditory function.

In order to determine the external and internal reliability for measuring speaking times and categorization of the subjects by their number of part-word repetitions, ten speech samples were selected at random from the 73 male subjects who participated in this study and these samples were analyzed by an experienced clinician and the experimenter ten days after their collection. One of the ten speech samples was thrown out when the student's speech was masked by an extraneous noise preventing the analysis of the sample. Pearson product-moment $I$ correlation coefficients were obtained at 0.93 and 0.96 respectively for inter-judge and intra-judge reliability. Total agreement was obtained between and within judges on the presence or absence of the part-word repetitions.

of the 73 male students who volitionally participated in the study, 20 subjects were selected to receive the peripheral and central auditory evaluations. The 10 subjects with the greatest number of part- 
word repetitions produced during a 500 word speech sample were selected from the 73 volunteers as the disfluent group. An additional group of 10 subjects were selected according to the following criteria: (1) they produced no part-word repetitions during a 500 word speech sample; and (2) their speaking times matched those of the subjects in the disfluent group. Each subject within this group, the fluent group, specifically met these criteria.

Table 2 presents the subjects' academic class levels, speaking times and total number of part-word repetitions during a 500 word speech sample. The means and standard deviations for speaking rates and partword repetitions for each of the two subject groups are listed in Table 3. Part-word repetitions in the fluent group were nonexistent and partword repetitions of the disfluent group averaged 6.6 per 500 words and ranged from 4 to 14 per 500 words. A student's t-test demonstrated that there was no significant difference between the speaking times of the two groups, thus controlling speaking rate, which is also illustrated in Table 3. All of the subjects were tested audiologically and met the following selection criteria: (1) normal middle ear functioning bilaterally as determined by impedance audiometry; (2) bilateral pure tone thresholds of $10 \mathrm{~dB} \mathrm{HL}$ or better for $500 \mathrm{~Hz}, 1000 \mathrm{~Hz}, 2000 \mathrm{~Hz}$, and $15 \mathrm{~dB} \mathrm{HL}$ or better for $400 \mathrm{~Hz}$; and (3) no history of stuttering or fluency problems as determined by a self-questionnaire. The selfevaluations were confirmed by the subjects' public speaking instructors who felt that they had no apparent fluency problems. No subjects had to be replaced because of a failure to meet the selection criteria. Each subject was also found to have peripheral speech discrimination ski11s 
within normal limits for both ears, as measured by recorded presentations of CID W-22 PB words.

The raw data, the total number correct on the Synthetic Sentence Identification-Ipsilateral Competing Message (SSI-ICM) test, used for the statistical analyses of the subjects' central auditory function are presented in Appendix C. Figure 6 illustrates the relationships between the mean scores for groups by ears. Table 4 presents the mean score and standard deviation for each group and ear tested. The significance of the difference among these means was evaluated by a split-plot $2 \times 2$ analysis of variance with one repeated measure (Kirk, 1968). The analysis of variance is summarized in Table 5. A coefficient of risk had been established at 0.10. The interaction effect between groups and ears was not significant. The main effect between groups was statistically significant but the main effect between ears was not significant. The relationship of the rank of each disfluent subject's number of part-word repetitions and the rank of their average SSI-ICM score for both ears is presented in Table 6 . A Spearman rho rank-order correlation coefficient was obtained at 0.854 , Indicating a significant positive correlation $(p<.01)$ between the rank of the number of part-word repetitions produced and the rank of the average SSI-ICM test scores for both ears obtained by the subjects in the disfluent group. This correlation suggests that the relationship between part-word repetitions and central auditory function found between fluent and disfluent groups may also be demonstrated within the disfluent group. 


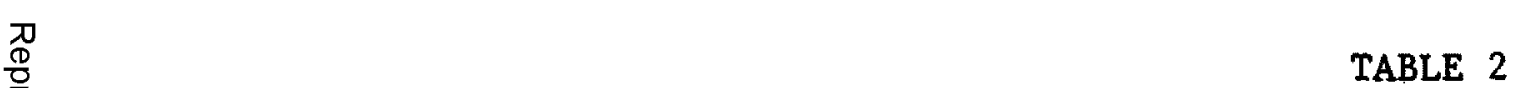

SUMMARY OF SUBJECTS ACADEMIC CLASS LEVELS, SPEAKING TIMES

AND NUMBER OF PART-WORD REPETITIONS DURING A 500 WORD SPEECH

\begin{tabular}{|c|c|c|c|c|c|c|c|}
\hline & \multicolumn{4}{|c|}{ DISFLUENT GROUP } & \multicolumn{3}{|c|}{ FLUENT GROUP } \\
\hline $\begin{array}{l}\text { Subject } \\
\text { Number }\end{array}$ & $\begin{array}{c}\text { Academic } \\
\text { Class } \\
\text { Level }\end{array}$ & $\begin{array}{l}500 \text { Word } \\
\text { Speaking } \\
\text { Time }\end{array}$ & $\begin{array}{l}\text { Part-Word } \\
\text { Repetitions }\end{array}$ & $\begin{array}{l}\text { Subject } \\
\text { Number }\end{array}$ & $\begin{array}{c}\text { Academic } \\
\text { Class } \\
\text { Level }\end{array}$ & $\begin{array}{l}\text { Speaking } \\
\text { Rate }\end{array}$ & $\begin{array}{c}\text { Part-Word } \\
\text { Repetitions }\end{array}$ \\
\hline 1. & Junior & $171 \mathrm{sec}$. & 4 & 1. & Junior & $174 \mathrm{sec}$. & 0 \\
\hline 2. & Sophomore & $185 \mathrm{sec}$. & 10 & 2. & Junior & $186 \mathrm{sec}$. & 0 \\
\hline 3. & Sophomore & $200 \mathrm{sec}$. & 5 & 3. & Sophomore & $202 \mathrm{sec}$. & 0 \\
\hline 4. & Senior & $177 \mathrm{sec}$. & 4 & 4. & Senior & $175 \mathrm{sec}$. & 0 \\
\hline 5. & Sophomore & $167 \mathrm{sec}$. & 4 & 5. & Sophomore & $165 \mathrm{sec}$. & 0 \\
\hline 6. & Freshman & $189 \mathrm{sec}$. & 4 & 6. & Sophomore & $191 \mathrm{sec}$. & 0 \\
\hline 7. & Junior & $177 \mathrm{sec}$. & 5 & 7. & Junior & $180 \mathrm{sec}$. & 0 \\
\hline 8. & Junior & $189 \mathrm{sec}$. & 14 & 8. & Junior & $191 \mathrm{sec}$. & 0 \\
\hline 9. & Senior & $197 \mathrm{sec}$. & 7 & 9. & Senior & $198 \mathrm{sec}$. & 0 \\
\hline 10 . & Sophomore & 179 sec. & 9 & 10. & Freshman & $180 \mathrm{sec}$. & 0 \\
\hline
\end{tabular}


Although the obtained differences in the SSI-ICM test scores for both groups suggest a slight right ear advantage as is often found in such tests, the difference between the ears was not statistically significant and could have occurred by chance. The results of the analysis of variance indicated that statistically significant differences exist between fluent normal speakers' and disfluent normal speakers' scores on the SSI-ICM test of central auditory function. These results support the experimental hypothesis that such a difference does exist that disfluent normal speakers demonstrate poorer scores on a test of central auditory function than do fluent normal speakers. 
FIGURE 7

MEAN SSI-ICM SCORES

OF GROUPS BY EARS

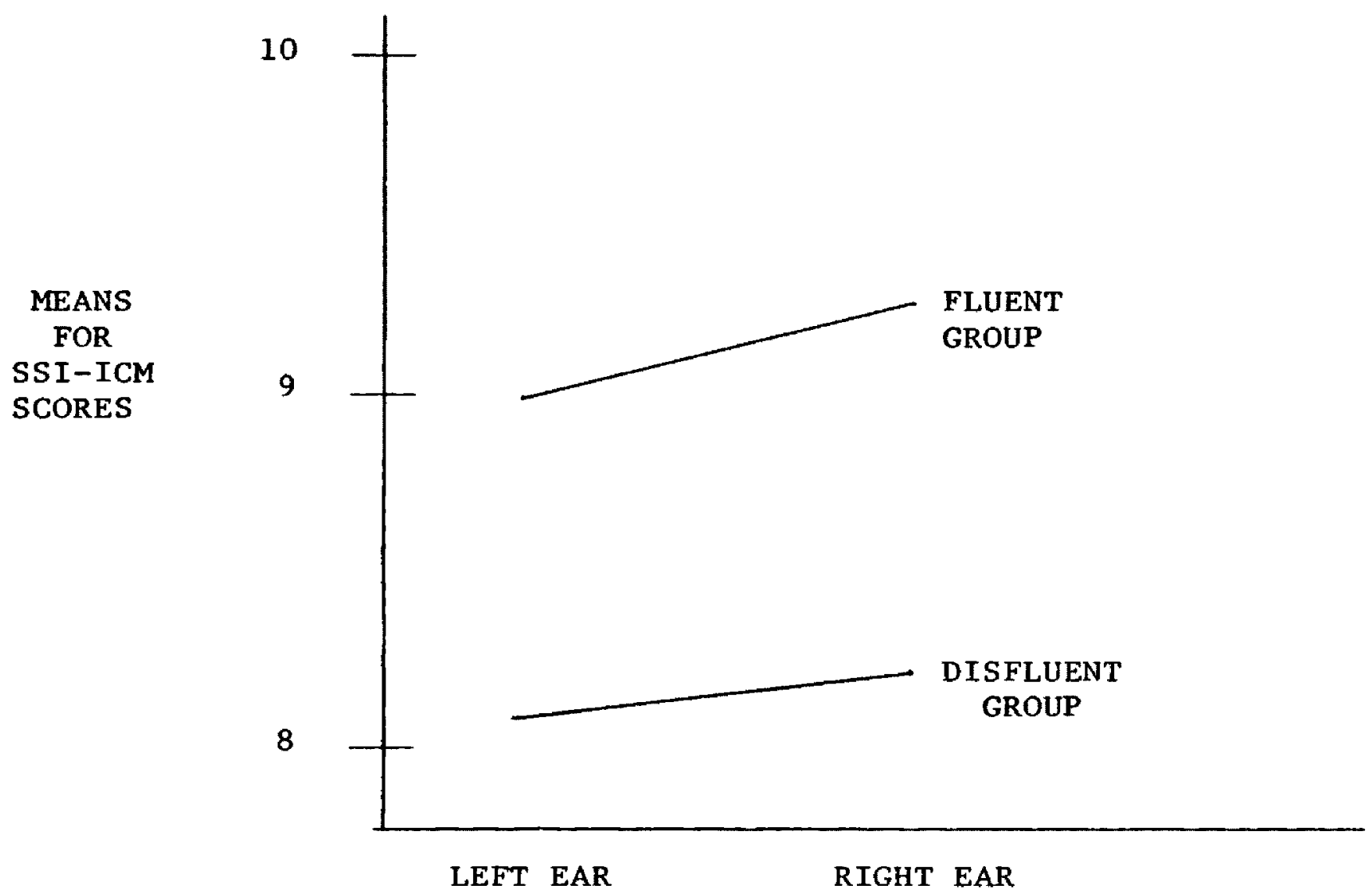


TABLE 4

MEANS AND STANDARD DEVIATIONS OF SSI-ICM

SCORES FOR GROUPS AND EARS TESTED

LEFT EAR

Mean
Standard

Deviation

\section{RIGHT EAR}

Mean

Standard

Deviation
FLUENT
GROUP
9.0
1.30
9.2
0.52

\section{DISFLUENT}

GROUP

8.1

1.35

8.2

1.76 
SUMMARY OF ANALYSIS OF VARIANCE

OF SSI-ICM SCORES OF FLUENT AND DISFLUENT SPEAKERS

FOR RIGHT \& LEFT EARS

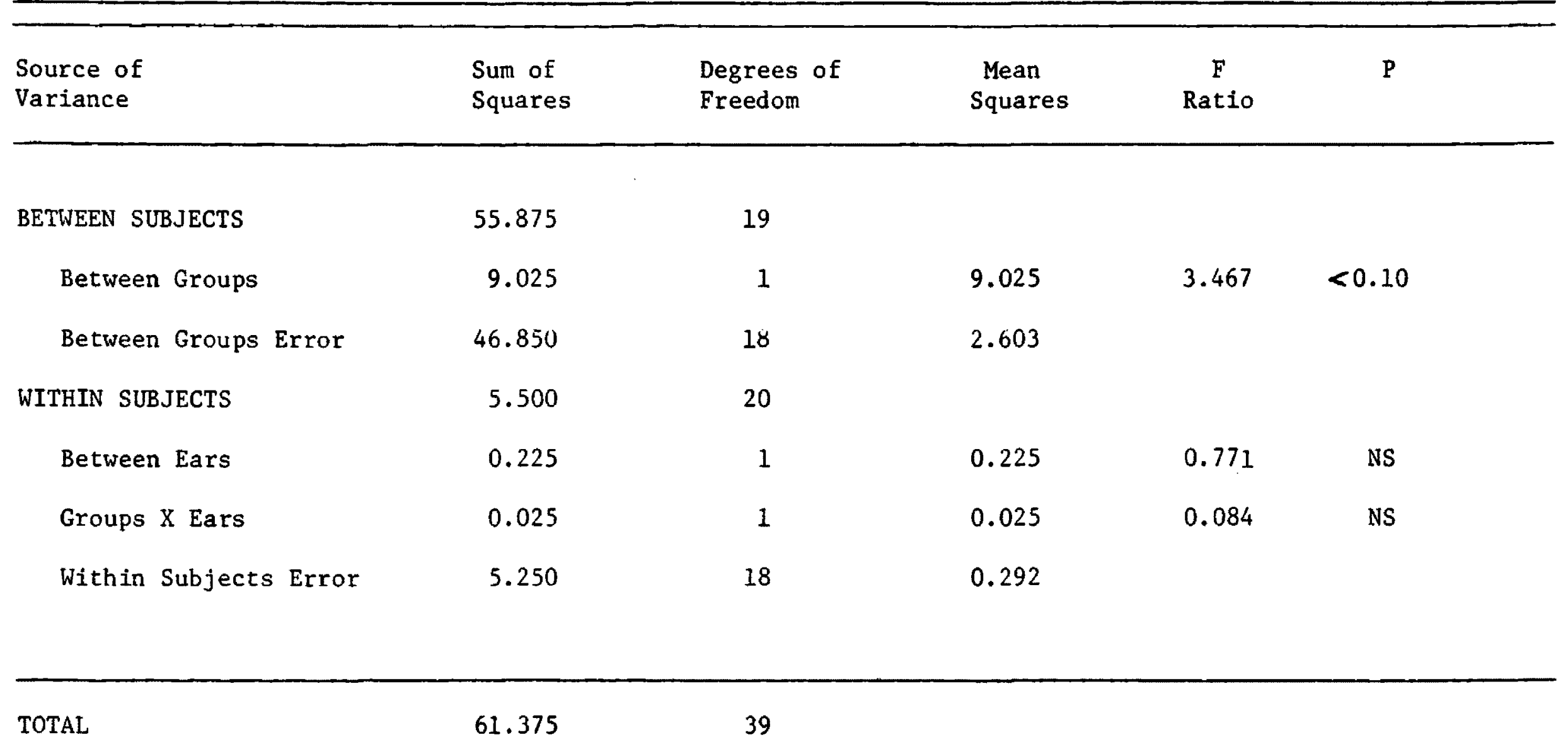

F 0.10, df $1 / 18=3.01$ 
TABLE 6

SPEARMAN ThO RANK-ORDER CORRELATION COEFFICIENT AND

THE RANKS OF THE DISFLUENT SUBJECTS'

NUMBER OF PART-WORD REPETITIONS AND

AVERAGE SSI-ICM SCORE FOR BOTH EARS

\begin{tabular}{|c|c|c|c|c|}
\hline & $\begin{array}{c}\text { NUMBER OF } \\
\text { PART - WORD } \\
\text { REPET ITIONS } \\
\end{array}$ & $\begin{array}{c}\text { AVERAGE SSI-ICM } \\
\text { SCORE FOR } \\
\text { BOTH EARS } \\
\end{array}$ & rho & $p$ \\
\hline $\begin{array}{l}\text { Subject } \\
\text { Number }\end{array}$ & Rank & Rank & & \\
\hline 1. & 7.5 & 9.5 & & \\
\hline 2 . & 2.0 & 2.0 & & \\
\hline 3. & 5.5 & 6.0 & & \\
\hline 4. & 7.5 & 6.0 & & \\
\hline 5. & 7.5 & 9.5 & 0.854 & $<0.01$ \\
\hline 6. & 7.5 & 8.0 & & \\
\hline 7. & 5.5 & 3.5 & & \\
\hline 8. & 1.0 & 1.0 & & \\
\hline 9. & 4.0 & 3.5 & & \\
\hline 10 & 3.0 & 6.0 & & \\
\hline
\end{tabular}

Critical Value of rho at $0.01, \mathrm{n}$ of $10=0.794$ 
CHAPTER V

DISCUSSION

The purpose of the present study was to investigate whether any central auditory differences existed between a group of disfluent normal speakers and a group of fluent normal speakers. The literature investigating auditory processing systems has demonstrated "subtle" differences in the central auditory function between stutterers and nonstutterers (Toscher and Rupp, 1978; Hall and Jerger, 1978; Sommers, Brady, and Moore, 1975). Differences between stutterers and nonstutterers on various other features have also been found to exist between groups of disfluent and fluent normal speakers, suggesting that the variables effecting fluency behavior lie along a continuum, with stutterers and nonstutterers overlapping in regard to a number of features (Bloodstein, 1975). The present author therefore hypothesized that if "subtle" central auditory differences exist between stutterers and nonstutterers then similar differences may be demonstrated between disfluent and fluent normal speakers.

The results of the present study revealed that statistically significant differences do exist between disfluent normal speakers' and fluent normal speakers' scores on the Synthetic Sentence IdentificationIpsilateral Competing Messages (SSI-ICM) test at a message-to-competition ratio value of -20 , a procedure that has been demonstrated to be sufficiently sensitive in measuring central auditory function. Although the scores of the present study were slightly higher than those which would have been predicted by Jerger's (1973) norms; the scores from 
both groups were consistent with the scores of the nonstutterers' scores on the SSI-ICM test in Toscher and Rupp (1978) as well as in Hall and Jerger (1978). An evaluation of the raw data from the disfluent subjects revealed a significant positive correlation between the ranks of the number of part-word repetitions produced and the rank of the average SSI-ICM test scores for both ears. That is, the subjects who produced the greatest number of part-word repetitions generally produced the most errors on the SSI-ICM test at a message-to-competition ratio value of -20 .

Although the present results were consistent with those of Toscher and Rupp (1978) and Hall and Jerger (1978), these results do not support those authors' interpretations that stutterers possess a different neurophysiological organization from that of nonstutterers. This difference in the neurophysiological organization is manifested by difficulties in the stutterer's auditory processing function which consequently adversely affects the speech monitoring system and results in the production of disfluencies. Nor do these results support the hypothesis that stutterers possess neurologically based auditory processing dysfunctions when compared to nonstutterers. Rather the present results are consistent with the hypothesis of Curry and Gregory (1969) that the underlying mechanism disrupting the appropriate auditory processing of speech signals may also be related to the disruption of the neurological feedback circuit that permits the uninterrupted forward flow of speech. Thus, the present study suggests that certain disfluencies, especially those disfluencies which suggest a breakdown in syllable production such as part-word repetitions, may arise from a central auditory deficit in 
processing the speech signals.

Therefore, it appears that a central auditory deficiency exists as at least one of the etiologies in the production of disfluent speech, whether or not the individual is or has been clinically diagnosed as a stutterer or possessing a communication disorder, stuttering. However, as Toscher and Rupp (1978) point out, other parameters considered in the literature cannot be ruled out as having an influence on or an etiological base for the production of disfluent speech. Parameters such as personality characteristics, the historical environmental milieu (learning), and linguistic formulation skills certainly will have an effect on the fluency of the speaker, both in their interaction with and apart from the speaker's central auditory function. Further studies must be undertaken before any definitive statement of etiology of disfluent speech. In addition, the results obtained in the present study strongly suggest that investigations into the nature of speech fluency should focus on the etiology of specific behaviors such as types of disfluencies and not on the etiology of some larger more abstract category such as "stuttering" or "stutterers".

Still the results of the study are not inconsistent with certain arguments which may account for many of the components thought to play some role in the production of disfluent speech. The interaction between the auditory servomechanism and speech fluency has been discussed earlier in the review of the literature. Basically the cybernetic theory of stuttering proposes that fluency disruption results from the asynchroization of simultaneous and successive bilateral motor 
responses due to a perceptual deficit or disturbance in the auditory monitoring system (Van Riper, 1973). The present study does not negate that the perceptual disturbance of the auditory monitoring system may be the result of a central auditory deficiency. Drawing from Fairbank's (1954) model of the speech servomechanism, it is proposed that as an individual produces speech, the auditory signal of that speech is delivered undistorted to the speaker's cochlea in which the signal is translated into neurological electrical impulses. These impulses then travel through the central auditory pathways which organize and integrate these impulses into a pattern which may be perceived and comprehended by the speaker. If this pattern which has been fed back through the auditory system is incongruent with the pattern which was intended, the speaker will then attempt to change the production of the speech signal until the perceived signal pattern is consistent with the intended signal pattern. The result of the modification of the speech signal may be an interruption in the forward flow of speech possibly seen as a part-word repetition or sound prolongation. The present study suggests that the neural pattern of the auditory signal may have been distorted through a central auditory deficiency and consequently produces a discrepancy between the perceived signal and the intended signa1. The speaker will then attempt to reduce the discrepancy by altering his speech production, which is in turn processed differently in the central auditory system, until the discrepancy between the intended signal and the perceived signal is resolved. Wingate (1969) has noted that disfluency production is sharply affected when stutterers sing, speak in chorus, whisper, speak under 
masking noise, speak during conditions of delayed sidetone, or adopt a foreign accent. In a subsequent article, Wingate (1970) suggested that the reductions in disfluency production associated with these various modifications of auditory function may be the adventitious result of certain changes in vocalization induced by the alterations in the auditory feedback of the speech signal. This statement is consistent with the interpretations drawn from the results of the present study. For example, attenuating the intensity and/or masking the auditory feedback signal, the amount of the primary speech signal being processed through the central auditory system is reduced which forces the speaker to rely on the tactile and proprioeptive feedback signals and consequently facilitating a more fluent forward flow of speech. Delayed auditory feedback similarly alters the auditory feedback by changing the temporal characteristics of the air conducted signal into the auditory system. Black (1951) and Lee (1951) reported that a normal speakers' speech slows down and they observed that the normal speakers increase the number of repetitions of syllables and prolongations of sounds which tend to resemble stuttering when the speech signal is returned to his ears via air conduction a fraction of a second after the time it would normally arrive. Individual differences in terms of the parameters required to produce the delayed auditory feedback effect may be directly related to the degree of integrity of the speaker's central auditory system, that is, the speaker with poorer central auditory processing skills may be more susceptible to the delayed auditory feedback effect. In addition, most. speakers generally slow down their rate of speech, overarticulate 
and/or concentrate on proprioceptive and tactile monitoring of their speech in an attempt to overcome the fluency disruption of the delayed auditory feedback (Bloodstein, 1975.) Van Riper (1970) suggested that stutterers respond in similar fashion to delayed auditory feedback and in turn generalize these behaviors to decrease their stuttering as we11. If a central auditory dysfunction is the basis for the fluency disruption under delayed auditory feedback conditions, slowing down the speech rate may allow time for proprioceptive and tactile feedback of the speech thus avoiding the central auditory monitoring of the signal as much as possible or it may allow more time to facilitate the integration of the auditory feedback signals into organized patterns by the central auditory mechanism which may be more readily perceived and comprehended by the speaker himself.

An article by Mackay (1958) has suggested that the amount of disfluency under delayed auditory feedback and the peak interference delay are related to some unknown factor or factors determining the maximum rate of speech and that this factor is age-linked, varying inversely with age. The study demonstrated that the number of speech disturbances under delayed auditory feedback was greater for 4 to 6 year old children than that for 7 to 9 year old children which in turn was greater than that for adults, regardless of the delay interval in the feedback. The present study suggests that the factor which influences the degree of speech disturbance due to the delayed auditory feedback may possibly be related to central auditory competency. An informal analysis of Willeford's (1977) norms for his central auditory assessment battery indicates that a child's central auditory processing skills 
improve with age until age 9 when the scores for normal children closely approximate the scores of adults. Thus, it may be argued that as a child grows older, his central auditory system matures and his speech becomes less susceptible to the effects of delayed auditory feedback. Similarly, children with more competent auditory systems may be less susceptible to fluency breakdowns due to processing difficulties than those children with less competent systems. This may possibly also account for Williams and Marks' (1972) findings that stuttering and nonstuttering children significantly differed on auditory-vocal tasks. Although Manning and Riensche (1976) demonstrated that stuttering and nonstuttering children performed in a similar manner on auditory assembly tasks, the tasks themselves may not have been sufficiently sensitive to measure deficiencies in the central auditory mechanisms. Clearly, research is needed to examine the relationship between central auditory function and speech flow variables in young children.

Mackay (1968) also demonstrated temporal differences for the optimal delay for interference between children and adults, with the adults requiring shorter delay intervals for maximum speech disturbances during delayed auditory feedback. The question of the central processing of the temporal parameters (frequency, phase and duration) of auditory signals in stutterers has been recently investigated by a number of articles. Stromstra (1972) measured the interaural phase disparity for seven frequencies of binaural bone-conducted sinusoidal auditory signals and binaural sinusoidal auditory signals for a group of stutterers and a group of nonstutterers. The results demonstrated 
significant differences between the two groups. Although Manning and Riensche (1976) demonstrated similar performances on auditory assembly tasks between stuttering and nonstuttering children, the authors found that stuttering children performed significantly better than did the nonstuttering children on meaningful CVC stimuli with silent interphonemic intervals of $300 \mathrm{msec}$. McFarlane and Prins (1978) demonstrated that stutterers are slower than nonstutterers in neural response times for a number of response tasks for both auditory and visual stimuli modes; however, significant differences were found for only the auditory stimulus mode. These authors interpreted the results to suggest that the auditory mechanism is, at least, one contributor to the slower neural response times as well as to the generally slower reaction times in stutterers. Finally a study by Peters, Love, Otto, Wood and Benignus (1976) indicated that stutterers have brain potentials for processing auditory information which are different from those of normal speakers. Furthermore, these authors demonstrated that stutterers show a more prolonged contingent negative variation prior to speaking "frequently stuttered" words compared to "never stuttered" words as well as when anticipating the production of a feared word compared to when preparing to say a nonfeared word.

Although the results of the present study are not inconsistent with those studies which suggest that a deficiency in processing of the temporal parameters in the central auditory system is an underlying cause of disfluency production, they cannot differentiate which central auditory parameters are affected or deficient. Rather, the present study suggests that a deficiency exists somewhere within the disfluent 
speaker's central auditory mechanism which may be best demonstrated in a figure-ground auditory discrimination task. Specifically disfluent normal speakers were found to have generally more difficulty identifying a primary message from a louder competing message than did the fluent normal speakers. This interpretation is consistent with the results of Toscher and Rupp (1978), who used a similar procedure testing the central auditory differences between stutterers and nonstutterers, as well as with the findings of Hall and Jerger (1978), who analyzed central auditory function between stutterers and nonstutterers with a number of instruments. With the exception of the acoustic reflex amplitude function measures, the authors found differences on the Synthetic Sentence Identification-Ipsilateral Competing Messages (SSI-ICM) subtests and the Staggered Sfondaic Word test, two procedures which require the listener to differentiate between two different signals. The dichotic listening tasks used in a number of studies demonstrating auditory differences between stutterers and nonstutterers have also required the listeners to separate signals from one another (Curry and Gregory, 1969; Perrin, 1970; and Eisenson, 1970; Sommers, Brady, and Moore, 1975; Sussman and MacNeilage, 1975).

In addition, the studies which have demonstrated auditory differences between stutterers and nonstutterers using dichotic 1istening tasks have suggested that stuttering may be the result of an incomplete hemisphere dominance for speech production, supporting the cerebral dominance theory developed by Lee Travis (1931; 1978a; 1978b). In this theory, the speech disruption is seen as the result of a general reduction in cortical lead control and is viewed as a neuro- 
physiological disturbance. Tsunda and Mariyama (1972) suggest that abnormal cortical function due to minimal brain damage is the underlying cause for speech disfluency. Peters et al. (1976) also lends support that the neurological deficiency resides at the cortical level. However, the present results suggest that a deficiency exists in the brain stem areas of the central auditory mechanism of disfluent speakers since poor performances on the Synthetic Sentence IdentificationIpsilateral Competing Message (SSI-ICM) test are characteristic of brain stem lesions. This statement receives strong support from the studies by Toscher and Rupp (1978) and Hall and Jerger (1978) which also employed audiological procedures which are sensitive to lesions in the auditory tracts at the brain stem level. Furthermore, the literature has demonstrated that differences in stapedial reflex function exist between stutterers and nonstutterers, which suggests that the auditory differences found in the research arise from differences in the lower brain stem integrity between the two groups (Horowitz et al. 1978; Hall and Jerger, 1978).

In summary, the results of the present study demonstrated that disfluent normal speakers scored significantly lower than fluent normal speakers on the Synthetic Sentence Identification-Ipsilateral Competing Message (SSI-ICM) test at a message-to-competition ratio value of -20 . This suggests that a neurologically based auditory processing deficiency may be at least one of the etiologies for the production of disfluencies, especially those disfluencies which may be related to the breakdown of syllable production. These results are consistent with previous findings in the literature indicating differences in the central auditory 
skills between stutterers and nonstutterers. Although these findings suggest that a breakdown in the central auditory processing of the speech feedback signal may lead to the production of disfluent speech, other variables affecting fluency behaviors may interact with or apart from the central auditory deficiency to produce disfluent speech. Clearly much more research is needed in this area before any definitive statement may be made regarding the etiology of disfluent speech in general and of stuttering in particular.

Recommendations for Further Research

Information obtained from the present study indicated a number of suggestions for future investigations which are listed below.

1. The present study should be replicated using several more subjects in both the fluent and disfluent groups. By increasing the number of subjects in each group, the study should be able to employ more stringent confidence levels for determining the probability of any differences obtained. In addition, larger samples may provide further information describing the relationship between the integrity of the subjects' central auditory mechanisms and speaking rates as well as the relationship between the severity of any central auditory deficiency and the severity of fluency breakdown.

2. Further studies should be undertaken using similar procedures to the procedures employed in the present study and investigate the relationship between central auditory function and production of disfluent speech with subjects who vary across a number of parameters. Personality characteristics, intelligence, language skills, age and sex are just a few of the variables which have been found to differentiate 
stutterers from nonstutterers. These variables should also be investigated in terms of their influence on scores measuring the central auditory function between fluent and disfluent normal speakers. For example, could similar results suggesting that disfluent speech arise from a central auditory deficiency in the speaker be obtained using female subjects.

3. The present study demonstrated differences between fluent normal speakers' and disfluent normal speakers' scores on the Synthetic Sentence Identification-Ipsilateral Competing Message (SSI-ICM) test at at a message-to-competition ratio value of -20 , a procedure that has been determined to be sensitive in measuring central auditory function. The recent emphasis in central auditory disorders in the literature has provided audiologists with a wide variety of instruments designed to assess central auditory disorders and identify the site of lesions in the mechanism involved. Future research should be directed to measure fluent, disfluent normal and stuttering speakers' central auditory mechanisms with different central auditory test instruments. Special attention should be made regarding the measures and procedures used in these instruments as well as to the aspects of the mechanism which they proclaim to evaluate.

4. Finally, research should be directed to replicate the previous studies investigating the central auditory function of stutterers and nonstutterers by using three subject groups: fluent normal speakers, disfluent normal speakers and stutterers. The present study suggests that the inconsistency in demonstrating differences between the central auditory functions of stutterers and nonstutterers may be due to a lack 
of homogeneity of the central auditory abilities of the nonstuttering groups as well as within the stuttering groups. Only by controlling for the difference in the central auditory functions between fluent normal speakers and disfluent normal speakers can studies discuss the presence or lack of central auditory differences between stutterers and nonstutterers. In addition, future studies should be more explicit in defining "fluent-disfluent" speaker or "stutterer-nonstutterer" differences on the basis of more specific behaviors rather than on these more ambiguous categories. 
CHAPTER VI

SUMMARY AND CONCLUSIONS

The purpose of the present study was to investigate whether any central auditory differences existed between a group of disfluent normal speakers and a group of fluent normal speakers. It was hypothesized that the disfluent group would demonstrate significantly lower scores on the Synthetic Sentence Identification-Ipsilateral Competing Message (SSI-ICM) test than would the fluent group; however, right earleft ear differences and the interaction between the groups and ears measured would not be significant. The procedure involved the administration of the SSI-ICM test at a message-to-competition ratio value of -20 to two groups of college students enrolled in an introduction to public speaking course at the University of Montana. The first group (the disfluent group) consisted of 10 male subjects who demonstrated the greatest number of part-word repetitions in a 500 word speech sample. The second group (the matched fluent group) consisted of 10 male subjects who did not produce any part-word repetitions in a 500 word speech sample and whose speaking times were matched with those of the disfluent group. The subjects in both groups were required to meet the following selection criteria: (1) normal middle ear functioning bilaterally as determined by impedance audiometry; (2) bilateral pure tone thresholds of $10 \mathrm{~dB} \mathrm{HL}$ or better for $500 \mathrm{~Hz}, 1000 \mathrm{~Hz}, 2000 \mathrm{~Hz}$, and $15 \mathrm{~dB} \mathrm{HL}$ or better for $4000 \mathrm{~Hz}$; and (3) no history of stuttering or fluency problems as determined by a self-questionnaire. Each subject was also found to have peripheral speech discrimination skills within 
normal limits for both ears.

The results of the study indicated that statistically significant differences exist between fluent normal speakers' and disfluent normal speakers' scores on the SSI-ICM test of central auditory function. Although an informal observation suggested that a right ear advantage may exist for both groups, the difference was too small to not warrant any comment about ear advantage. Furthermore, the results indicated that the interaction between fluent-disfluent groups and right ear-left ear advantage was not significant. It was suggested that a centra1 auditory deficiency, at least at the brain stem level, may possibly be one of the etiologies for the production of disfluent speech, especially those disfluencies possibly due to a breakdown in syllable production. The implications of the present results on previous studies' interpretations of the relationship between central auditory function and fluency breakdown were discussed. Recommendations for further research were also presented. 


\section{BIBLIOGKAPHY}




\section{B IBLIOGRAPHY}

Albright, M. A. H., and Malone, J. Y. The relationship of hearing acuity to stammering. Journal of the International Council for Exceptiona 1 Children, 8, 1942, 186-190.

Backus, 0. Incidence of stuttering among the deaf. Annals of otology, Rhinology, and Laryngology, 47, 1938, 632-635.

Black, J. The effect of sidetone delay upon vocal rate and intensity. Journal of Speech and Hearing Disorders, 16, 1951, 56-61.

Bloodstein, o. A Handbook on Stuttering. Chicago, Illinois: The National Easter Seal Society for Crippled Children and Adults, 1975.

Bocca, E., and Calearo, C. Central hearing processes. In J. Jerger (Ed.): Modern Developments in Audiology, pp. 337-370. New York: Academic Press, 1963.

Brunt, M. The staggered spondaic word test. In J. Katz (Ed.): Handbook of Clinical Audiology, pp. 262-275. Baltimore, Maryland: The Williams \& Wilkins Company, 1978.

Butler, K., Hedrick, D., and Manning, C. Composite Auditory Perceptual Test. Hayward, California: Alameda County School Department, 1973.

Butler, R. R., and Stanley, P.E. The stuttering problem considered from an automatic control point of view. Folia Phoniatricia, 18, $1966,33-44$.

Carhart, R. Special hearing tests for otoneurologic diagnosis. Archives of Otolaryngology, $89,1969,38-45$.

Cerf, A., and Prins, D. Stutterers' ear preference for dichotic syllables. Paper presented at the American Speech and Hearing Convention, Las Vegas, Nevada, 1974.

Cherry, C., and Sayers, B. Experiments upon the total inhibition of stammering by external control and some clinical results. The Journal of Psychosomatic Research, 1, 1956, 233-246.

Conture, E. G., and Brayton, E. R. The influence of noise on stutterers' different disfluency types. Journal of Speech and Hearing Research, $18,1975,381-384$. 
Cross, D. E., Shadden, B. B., and Luper, H. L. Effects of stimulus ear presentation on the voice reaction time of adult stutterers and nonstutterers. Journal of Fluency Disorders, 4, 1979, 45-58.

Curry, F. K. W., and Gregory, H. H. The performances of stutterers on dichotic listening tasks though to reflect cerebral dominance. Journal of Speech and Hearing Disorders, 12, 1969, 73-82.

Dorman, M. F., and Porter, R. J. Hemispheric lateralization for speech perception in stutterers. Cortex, 11, 1975, 181-185.

Fairbanks, G. Systemic research in experimental phonetics: 1 . A theory of the speech mechanism as a servosystem. Journal of Speech and Hearing Disorders, 19, 1954, 133-139.

Flowers, A., Costello, M., and Small, V. Flowers-Costello Tests of Central Auditory. Abilities. Dearborn, Michigan: Perceptual Learning Systems, 1973.

Gregory, H. H. Stuttering and auditory central nervous system disorder. Journa 1 of Speech and Hearing Research, 7, 1964, 335-341.

Gruber, L. Sensory feedback and stuttering. Journal of speech and Hearing Disorders, 30, 1965, 378-380.

Hall, J. W., and Jerger, J. Central auditory function in stutterers. Journal of Speech and Hearing Research, 21, 1978, 324-337.

Ha rms, M. A., and Malone, J. Y. The relationship of hearing acuity to stammering. Journal of Speech and Hearing Disorders, 4, 1939, 363-370.

Horovitz, L. J., Johnson, S. B., Pearlman, R. C., and Schaffer, E. J. Stapedial reflex and anxiety in fluent and disfluent speakers. Journal of Speech and Hearing Research, 21, 1978, 762-767.

Jerger, J. Diagnostic audiology. In J. Jerger (Ed.) : Modern Developments in Audiology, pp. 75-115. New York: Academic Press, 1973.

Jerger, J., and Jerger, S. Auditory findings in brainstem disorders. Archives of otolaryngology, 99, 1974, 342-349.

Jerger, J., and Jerger, S. Clinical validity of central auditory tests. Scand. Audio1., 4, 1975, 147-163.

Jerger, J., Speaks, C., and Tramme11, J. H. A new approach to speech audiometry. Journal of Speech and Hearing Disorders, 33, 1968, 318-328. 
Johnson $W$. Measurements of oral reading and speaking rate and disfluency of adult male and female stutterers and nonstutterers. Journal of $\frac{\text { Speech }}{\text { No. } 7,1961,1-20}$. Hearing Disorders, Monograph Supplement,

Katz, J. The use of staggered spondaic words for assessing the integrity of the central auditory nervous system. Journal of Audiological Research, 2, 1962, 327-337.

Katz, J. The SSW test: An interim report. Journal of Speech and Hearing Disorders, 33, 1968, 132-146.

Katz, J. The SSW test manua1. Brentwood, Missouri: Auditec of St. Louis, 1973 .

Katz, J. The staggered spondaic word test. In R. W. Keith (Ed.): Central Auditory Dysfunction, pp. 103-121. New York: Grune and Stratton, 1977.

Lee, B. S. Artificial stutterer. Journal of Speech and Hearing Disorders, 16, 1951, 56-61.

Lynn, G. E., Benitez, J. T., Eisenbrey, A. B., Gilroy, J., and Wilner, H. I. Neuro-audiological correlates in cerebral hemisphere lesions; temporal and parietal lobe tumors. Audiology, 11, 1972, 11-134.

Lynn, G. E. and Gilroy, J. Neuro-audiological abnormalities in patients with temporal lobe tumors. Journal of Neurological Science, 17, $1972,167-184$.

Lynn, G. E., and Gilroy, J. Central aspects of audition. In J. Northern (Ed.): Hearing Disorders, pp. 102-117. Boston, Massachusetts: Little, Brown and Company, 1976.

Mackay, D. G. Metamorphosis of a critical interval: Age-linked changes in the delay in auditory feedback that produces maximal disruption of speech. The Journal of the Acoustical Society of America, 43, $1968,811-821$.

Manning, W. H., and Riensche, L. Auditory assembly abilities of stuttering and nonstuttering children. Journal of Speech and Hearing Research, $19,1976,777-783$.

Martin, J. E. The signal detection hypothesis and perceptual defect theory of stuttering. Journal of Speech and Hearing Disorders, $35,1970,252-255$.

Matzker, J. The binaural test. The Journal of International Audiology, $1,1962,209-211$. 
McFarlane, S. C. and Prins, C. Neural response time of stutterers and nonstutterers in selected oral tasks. Journal of Speech and Hearing Research, 21, 1978, 768-778.

Mysak, E. D. Servo theory and stuttering. Journal of Speech and Hearing Disorders, 30, 1965, 378-380.

Mysak, E. D. Speech pathology and feedback theory. Springfield, Illinois: Charles C. Thomas, 1966 .

Perkins, W. H. Speech pathology: An applied behavioral science. St. Louis, Missouri: The C. V. Mosby Company, 1977.

Perrin, K. An examination of ear preference for speech and nonspeech stimuli in a stuttering population. Dissertations Abstracts, $30,1970,1213$.

Perrin, K., and Eisenson, J. An examination of ear preferences for speech and nonspeech stimuli in a stuttering population. Paper presented at the Annual Convention of the American Speech and Hearing Association, New York, 1970.

Peters, R. W., Love, L., otto, D., Wood, T., and Benignus, V. Cerebral processing of speech and non-speech signals by stutterers. In Kroebell (Ed.): Proceedings XVIth International Congress of Logopedics and Phoniatrics: Interlaken, 1974, pp. 384-388. Basel: S. Karger, 1976. (Abstract)

Polsin, J. H. Communicating with an audience: Introductory exercises. Dubuque, Iowa: Kenda11/Hunt Publishing Company, 1976.

Quinn, P. T. Stuttering: Cerebral dominance and the dichotic word test. The Medical Journal of Australia, 2, 1972, 639-643.

Sander, E. K. Reliability of the Iowa Speech Disfluency Test. Journal of Speech and Hearing Disorders, Monograph Supplement, No. 7, $\overline{19} 6 \overline{1,21-30}$.

Sommers, R. K., Brady, W. A., and Moore, W. H. Dichotic ear preferences of stuttering children and adults. Perceptual and Motor Ski11s, 41, 1975, 931-938.

Speaks, C., and Jerger, J. Method for measurement of speech identification. Journal of Speech and Hearing Research, 8, 1965, 185-194.

Stetson, R. Motor phonetics: A study of speech movements in action. Amsterdam: North-Holland Publishing Company, 1951.

Stromstra, C. A methodology related to the determination of the phase angle of bone conducted speech sound energy of stutterers and nonstutterers. Dissertation Abstracts, 16, 1956, 1738-1739. 
Stromstra, C. Experimental blockage of phonation by distorted sidetone. Journal of Speech and Hearing Research, 2, 1959, 286-301.

Stromstra, C, Delays associated with certain sidetone pathways. The Journal of the Acoustical Society of America, 34, 1962, 392-39 $\overline{6}$.

Stromstra, C. Interaural phase disparity of stutterers and nonstutterers. Journal of Speech and Hearing Research, 15, 1972, 771-780.

Sussman, H. M., and MacNeilage, P. F. Studies of hemispheric specialization for speech production. Brain and Language, 2, 1975 , 131-151.

Timmons, B. A., and Boudrea, J. P. Auditory feedback as a major factor in stuttering. Journal of Speech and Hearing Disorders, 37, 1972, $476-484$.

Toscher, M. M. and Rupp, R. R. A study of the central auditory processes in stutterers using the synthetic sentence identification (SSI) test battery. Journal of Speech and Hearing Research, 21, 1978, 779-792.

Travis, L. Speech pathology. New York: Appleton-Century-Crofts, Inc., 1931.

Travis, L. Neurophysiological dominance. Journal of Speech and Hearing Disorders, 43, 1978, 275-277.

Travis, L. The cerebral dominance theory of stuttering: 1931-1978. Journal of Speech and Hearing Disorders, 43, 1978, 278-282.

Tsunoda, T., and Moriyama, H. Specific patterns of cerebral dominance for various sounds in adult stutterers. The Journal of Audiological Research, 12, 1972, 216-227.

Van Riper, C. The use of DAF in stuttering therapy. British Journal of Disorders of Communication, 5, 1970, 40-45.

Van Riper, C. The nature of stuttering. Englewood Heights, New Jersey: Prentice-Ha $\overline{11}$ Inc., 1971 .

Van Riper, C. The treatment of stuttering. Englewood Heights, New Jersey: Prentice-Hall, Inc., 1973.

Webster, R. L., and Lubker, B. B. Interrelationships among fluency producing variables in stuttered speech. Journal of Speech and Hearing Research, 11, 1968, 754-766.

Willeford, J. A, Competing Sentences for Diagnostic Purposes. Unpublished material, Colorado State University, Fort Collins, Colorado, 1968. 
Willeford, J. A. Central auditory function in children with learning disabilities. Journal of Audiology and Hearing Education, 2, $1976,12-20$.

Willeford, J. A. Assessing central auditory behavior in children: A test battery approach. In R. W. Keith (Ed.): Central Auditory Dysfunction, pp. 43-68. New York: Grune and Stratton, 1977a.

Willeford, J. A. Differential diagnosis of central auditory dysfunction. In L. Bradford (Ed.): Audiology: An Audio Journal for Continuing Education. New York: Grune and Stratton, $1977 \mathrm{~b}$.

Willeford, J. A. Sentence tests of central auditory dysfunction. In J. Katz (Ed.): Handbook of C1inical Audiology, pp. 252-261. Baltimore, Maryland: The Williams \& Wilkins Company, 1978.

Willeford, J. A., and Billger, J. M. Auditory perception in children with learning disabilities. In J. Katz (Ed.): Handbook of Clinical Audiology, pp. 410-425. Baltimore, Maryland: The Williams \& Wilkins Company, 1978.

Williams, A., and Marks, C. A comparative analysis of the ITPA and PPVT performance of young stutterers. Journal of Speech and Hearing Research, 15, 1972, 323-329.

Wingate, M. E. Sound and pattern in "artificial" fluency. Journal of Speech and Hearing Research, 10, 1969, 677-686.

Wingate, M. E. Effect on stuttering of changes in audition. Journal of Speech and Hearing Research, 11, 1970, 861-873.

Woodcock, R. Goldman-Fristoe-Woodcock Auditory Skil1s Test BatteryTechnical Manual. Circle Pines, Minnesota: American Guidance Services, 1976 .

Young, M. A. Predicting ratings of severity of stuttering. Journal of Speech and Hearing Disorders, Monograph Supplement, No. 7, 1961, 31-54. 
APPENDICES

Reproduced with permission of the copyright owner. Further reproduction prohibited without permission. 


\section{APPENDIX A}

\section{Subject \#}

\section{Se1f-Questionnaire}

1. Have you ever had a speech, language or hearing problem? If so, please describe.

2. Have you ever received speech therapy? If so, please describe.

3. Have you ever had "stuttering" or fluency problems? If so, please describe.

4. Has anyone ever told you that you "stutter" or have a fluency problem? If so, please describe. 


\title{
APPENDIX B
}

\section{SYNTHETIC SENTENCE IDENTIFICATION}

IPSILATERAL COMPETING MESSAGE

\begin{abstract}
This is a test of your ability to perceive ten sentences presented to one ear while that same ear receives a competing passage from Lewis Carroll's Alice in Wonderland. The ten sentences are systematically diverted from the standard rules of grammar and are presented on the score sheets in front of you. Each sentence will begin with the carrier phrase: "Ready" to provide you with a clue to its presentation. After you hear the sentence, identify the sentence you heard by circling the number of the sentence on the score sheet and then turn the page. The sentences are first presented alone, then to one ear with the competing message and then to the other ear. The competing passage is louder than the sentences, so you will have to listen carefully. Do you have any questions?
\end{abstract}

Please begin. 


\author{
APPENDIX B (cont.) \\ SYNTHETIC SENTENCE IDENTIFICATION \\ IPSILATERAL COMPETING MESSAGE \\ SCORE SHEET ${ }^{1}$
}

1. SMALL BOAT WITH A PICTURE HAS BECOME

2. BUILT THE GOVERNMENT WITH THE FORCE ALMOST

3. GO CHANGE YOUR CAR COLOR IS RED

4. FORWARD MARCH SAID THE BOY MAD A

5. MARCH AROUND WITHOUT A CARE IN YOUR

6. THAT NEIGHBOR WHO SAID BUSINESS IS BETTER

7. BATTLE CRY AND BE BETTER THAN EVER

8. DOWN BY THE TIME IS REAL ENOUGH

9. AGREE WITH HIM ONLY TO FIND OUT

10. WOMEN VIEW MEN WITH GREEN PAPER SHOULD

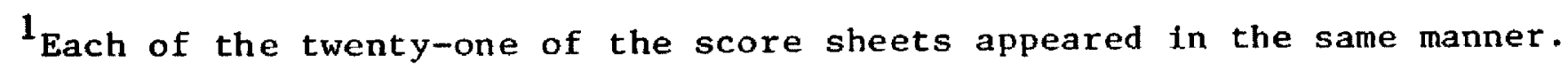


APPENDIX C

SCORES ON THE AUDIOLOGICAL TESTING

\begin{tabular}{|c|c|c|c|c|c|c|c|}
\hline Subject & Questionnaire & Peripheral & $\begin{array}{l}\text { SSI ICM } \\
\text { Scores }\end{array}$ & Subject & Questionnaire & Peripheral & $\begin{array}{c}\text { SSI-ICM } \\
\text { Scores }\end{array}$ \\
\hline Number & & & $\mathrm{AS} \quad \mathrm{AD}$ & & & & $\mathrm{AS} \quad \mathrm{AD}$ \\
\hline
\end{tabular}

\begin{tabular}{|c|c|c|c|c|c|c|c|c|}
\hline 1. & No & Negative & 10 & 10 & 1. & No & Negative & 10 \\
\hline 2. & No & Negative & 7 & 7 & 2. & No & Negative & 10 \\
\hline 3. & No & Negative & 8 & 8 & 3. & No & Negative & 8 \\
\hline 4. & No & Negative & 8 & 8 & 4. & No & Negative & 10 \\
\hline 5. & No & Negative & 10 & 10 & 5. & No & Negative & 9 \\
\hline 6. & No & Negative & 9 & 10 & 6. & No & Negative & 8 \\
\hline 7. & No & Negative & 7 & 8 & 7. & No & Negative & 7 \\
\hline 8. & No & Negative & 6 & 6 & 8. & No & Negative & 10 \\
\hline 9. & No & Negative & 8 & 7 & 9. & No & Negative & 9 \\
\hline 10. & No & Negative & 8 & 8 & 10 & No & Negative & 9 \\
\hline
\end{tabular}

